\title{
PETROGRAFIA, GEOQUÍMICA E GEOCRONOLOGIA DAS ROCHAS GRANÍTICAS DA OROGENIA SAN IGNÁCIO (BOLÍVIA)
}

\author{
GEOLOGY, GEOCHEMISTRY AND GEOCRONOLOGY OF THE GRANITIC ROCKS OF SAN \\ IGNÁCIO OROGENY (BOLÍVIA)
}

\author{
Gabriela Vargas-MATTOS ${ }^{1}$, Mauro César GERALDES ${ }^{1}$, Armando D. TAVARES JR. ${ }^{1}$, \\ Ramiro Matos SALINAS ${ }^{2}$, Wilson TEIXEIRA ${ }^{3}$ \\ ${ }^{1}$ Universidade do Estado do Rio de Janeiro (UERJ), Rua São Francisco Xavier, 524, Maracanã, Rio de Janeiro, Brasil. \\ E-mail: gvargas_mattos@hotmail.com; geraldes@uerj.br; tavares@uerj.br \\ ${ }^{2}$ Universidad Mayor de San Andrés (UMSA), Calle 27 de Cota Cota, Pabellon Geologia, Campus Universitário, Cota Cota, La Paz- \\ Bolivia. E-mail: rmatoss@yahoo.com \\ ${ }^{3}$ Instituto de Geociências, Universidade de São Paulo, Rua do Lago 562, Cidade Universitária, São Paulo - SP. \\ E-mail: wteixeira@usp.br \\ Introdução \\ Materiais e Métodos \\ Orogenia San Ignácio \\ Materiais e Métodos \\ Resultados \\ Granodiorito Cachuela \\ Sienogranito Motacusal \\ Granodiorito Talcoso \\ Caracterização Geoquímica \\ Caracterização Isotópica $\mathrm{U} / \mathrm{Pb}$ e $\mathrm{Sm} / \mathrm{Nd}$ \\ Evolução isotópica do Nd do precambriano boliviano \\ Correlações Geológicas \\ Discussões \\ Conclusões \\ Referências
}

\begin{abstract}
RESUMO - Esta contribuição visa caracterizar os granitos proterozoicos da Orogenia San Ignácio na parte ocidental da Bolívia, descrevendo a sua petrografia, composição química e isotópica de $\mathrm{U}-\mathrm{Pb}$ e $\mathrm{Sm} / \mathrm{Nd}$, com objetivo de identificar fontes e processos de formação destas rochas. Os resultados dos estudos das intrusões Cachuela, Motacusal e Talcoso, apresentam características químicas de granito do tipo A e as idade U/Pb obtidas em zircão estão entre 1307 e 1333 Ma. Os resultados isotópicos Sm-Nd mostram valores de $\varepsilon_{\mathrm{Nd}(0)}$ negativos entre $(-0,77$ e -3,86), aqui relatados indicam que o evento San Ignácio é representado por um arco magmático com participação de crosta continental previamente formada, representando um importante período colisional no Cráton Amazônico.

Palavras-chaves: Orogenia San Ignácio; Cráton Amazônico; Proterozoico; Bolivian pre-Cambrian.
\end{abstract}

\begin{abstract}
This contribution aims to characterize the Proterozoic granites of San Ignacio orogeny, western Bolivia, describing their chemical composition, $\mathrm{U}-\mathrm{Pb}$ and $\mathrm{Sm} / \mathrm{Nd}$ isotopic to identify sources and process of the crustal formation. The results of chemical and isotopic granitoids of Cachuela, Motacusal and Talcoso, present U/Pb age in zircon between 1307 and $1333 \mathrm{Ma}$, suggesting an important epoch of generation of granitoids in the Bolivian pre-Cambrian. Chemistry (A-Type granites) and $\mathrm{Nd}$ isotopes ( $\varepsilon_{\mathrm{Nd}(1330)}$ between -0.77 and -3.86) signatures here reported suggest an anorogenic environment and the spider diagram indicate the within-plates tectonic setting for the formation of these granites, instead of arc-related environment is suggested in the literature for these rocks. The data here reported suggest a geological evolution for the Bolivian pre-Cambrian composed of the San Ignacio event is represented by magmatic arc with participation of continental crust previously formed representing an important collisional period in the SW Amazonian craton.
\end{abstract}

Keywords: San Ignacio Orogeny; Amazonian craton; Proterozoic; Bolivian pre-Cambrian.

\section{INTRODUÇÃO}

Este trabalho trata da evolução tectônica da porção SW do Cráton Amazônico, por meio de investigações geológicas, geoquímicas e geocronológicas. Os estudos abrangem áreaschave do Pré-Cambriano Boliviano (Figura 1A) e o tema é relevante para a caracterização do magmatismo mesoproterozoico e suas implicações para a evolução crustal e reconstruções paleotectônicas (Cordani \& Brito Neves, 1982; Tohver et al., 2006; Cordani et al., 2007).
O extremo sudoeste do Cráton Amazônico (Figura 1B), que envolve o limite entre o estado de Mato Grosso com a Bolívia é uma região ainda pouco conhecida com relação a sua evolução magmática devido ao seu difícil acesso (Amaral, 1974; Menezes et al., 1993; Santos et al., 2000, 2008; Geraldes et al., 2013). Apesar dos trabalhos volumosos na literatura sobre a geologia do Pré-Cambriano boliviano, existem ainda muitas questões a respeito dos ambientes 
tectônicos de geração. Por exemplo, a unidade Lomas Manechis e La Chiquitania, consideradas por Litherland et al., (1986), como detentora das rochas mais antigas do bloco Paraguá e que abrange segmentos-chave da crosta précambriana Boliviana e terrenos correlatos com o SW do Cráton Amazônico no Brasil.

As orogenias San Ignácio e Sunsás (Tassinari et al., 2000; Geraldes et al., 2001; 2004; Teixeira et al., 2010) foram importantes eventos tectônicos e magmáticos, caracterizados por formarem extensas áreas, especialmente as intrusões no setor norte, mais conhecido como Complexo Pensamiento (Orogenia San Ignácio) e o setor centro sul
(Orogenia Sunsás). A área de estudo encontra-se no extremo leste da Bolívia e cobre uma extensão areal de $220.000 \mathrm{~km}^{2}$, sendo a maior parte do terreno intransitável e com exuberante vegetação. A área de trabalho (Figura 1A) encontra-se entre os povoados de San Ramón, San Javier, Las Maras, San Pablo e El Carmen, todas elas incluídas nas folhas topográficas Concepción (SE 20-3) e San José de Chiquitos (SE 20-7 SE 20-8), escala 1: 250 000 segundo o Instituto Geográfico Militar de Bolívia (IGM) e encontra-se inserida na Província Rondoniana-San Ignácio (Figura 1B), da subdivisão geotectônica do Cráton Amazônico proposta por Tassinari \& Macambira (2004).

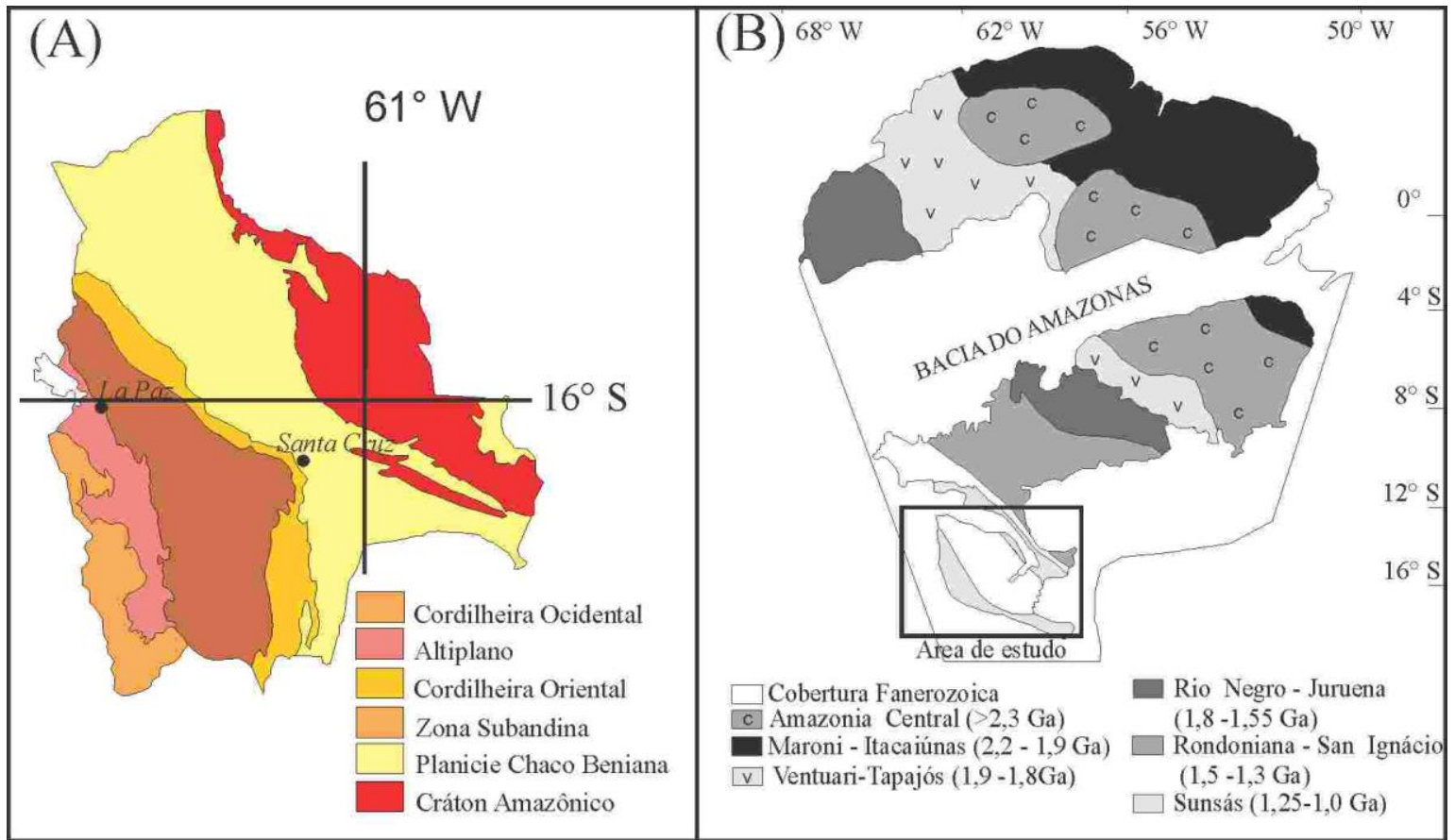

Figura 1- Mapa de localização da área de estudo. A) Subdivisão da Bolívia em províncias geológicas segundo Adamek et al. (1996). B) Subdivisão do Cráton Amazônico em províncias geológicas, segundo Tassinari \& Macambira (2004); Cordani \& Teixeira (2007).

Neste sentido é importante ressaltar que resultados $\mathrm{Sm}-\mathrm{Nd}$ e U-Pb sobre as rochas do Précambriano boliviano ainda são escassos, impossibilitando as correlações de caráter regional, embora nos últimos anos tenha-se obtido um importante avanço na compreensão dos processos evolutivos (Boger et al., 2005; Santos et al., 2008; Matos et al., 2009; VargasMattos, 2006; Teixeira et al., 2010; Bettencourt et al., 2009; Vargas-Mattos et al., 2009), além de propostas de reconstrução paleogeográficas (Hoffman, 1991; D'Agrella et al., 2008, 2012; Tohver et al., 2000).

Este trabalho tem por objetivo a caracterização petrográfica, geoquímica e isotópicas (U-Pb e $\mathrm{Sm}-\mathrm{Nd}$ ) das suítes graníticas segundo Litherland et al. (1986) e Adamek et al.
(1996) com base na cartografia geológica realizada pelo Serviço Geológico Britânico (baseados em idades $\mathrm{Rb} / \mathrm{Sr}$ e K/Ar).

$\mathrm{Na}$ região estudada foram amostrados os corpos graníticos considerados previamente como incluídos na Orogenia San Ignácio (Cachuela, Motacusal e Talcoso). Os resultados aqui apresentados são concordantes com esta postulação, indicando serem relacionadas ao Complexo Pensamiento.

Desta forma, pretende-se atingir estes objetivos mediante descriminações petrográficas, geoquímicas e isotópicas (U-Pb e Sm$\mathrm{Nd})$ com interpretações dos prováveis processos de evolução magmática, assim como também a caracterização da fonte através de estudos isotópicos de $\mathrm{Nd}$ e épocas de 
cristalização através do método U-Pb em zircão das rochas graníticas do Pré-Cambriano boliviano. A partir deste estudo regional pretende-se contribuir para a compreensão da evolução destes corpos graníticos do PréCambriano boliviano e propor as possíveis correlações com o SW do Cráton Amazônico no Brasil.

\section{OROGENIA SAN IGNÁCIO}

Segundo a literatura, o mais importante evento magmático do Pré-Cambriano boliviano corresponde às formações das suítes graníticas sin- e pós-tectônicas da Orogenia San Ignácio (Figura 2). Os afloramentos mais extensos fazem referência aos corpos intrudidos no setor norte, mais conhecido como Complexo Pensamiento. Estes corpos foram datados inicialmente nos anos 1980, com idades ( $\mathrm{Rb}-\mathrm{Sr}$ ) entre $1380 \mathrm{Ma}$ e $1285 \mathrm{Ma}$ por Litherland et al. (1986). Idades Rb-Sr em metassedimentos também resultam em valores por volta de 1,34 Ga sugerindo um importante evento magmáticometamórfico regional no Pré-Cambriano boliviano.

Boger et al. (2005) apresentaram resultados para o Complexo Pensamiento como um importante evento gerador de rochas graníticas com idades U$\mathrm{Pb}$ em zircões pelo método SHRIMP entre $1334 \pm 12$ e $1320 \pm 11$ Ma, obtidos a partir da intrusão granítica San Rafael. Este padrão de idade, entretanto, é observado tanto em rochas xistosas (bordas de zircões detríticos) como em rochas gnáissicas do Lomas Manechi (também bordas de zircões), sugerindo que o evento San Ignácio teve ampla atuação nos terrenos pré-cambrianos da Bolívia.

Além disso, Boger et al. (2005) reporta zircões com idades 1,34 Ga cujos núcleos apresentam idades de cerca de 1,68 Ga, sugerindo que o magmatismo do evento San Ignácio teve como fonte parcial, rochas da crosta mais antiga formada durante a orogênese Lomas Manechi.

Resultados Sm-Nd sobre as rochas do PréCambriano boliviano ainda são escassos, embora os últimos anos mostrassem importantes avanços a respeito (Santos et al., 2008 e Matos et al., 2009). As únicas unidades geradas no evento San Ignácio analisadas por este método são representadas pelos granitos: Puerto Alegre/La Junta com TDM com cerca de 1,99 Ga e 2,09 Ga e com valores de $\varepsilon N d$ negativos. E os granitos Diamantina e Orobaya com TDM entre 1,69 Ga e 1,73 Ga, com valores de $\varepsilon N d$ entre + 1,0 e $+1,4$, respectivamente, como representantes da Orogenia San Ignácio (Figura 2). Os valores apontam longas permanências crustais antes da cristalização dos granitos durante o evento San Ignácio, sugerindo uma importante participação ou mistura de crosta pré-formada na origem dos respectivos magmas.

Matos et al. (2009) apresentam treze análises químicas em rocha total para elementos maiores, traços e ETR do Complexo Granítico Pensamiento, assim como datações SHRIMP em zircões dos plútons sin- a tardi-cinemáticos La Junta com idade de1347 \pm 21 Ma e San Martin com idade de1373 \pm 20 $\mathrm{Ma}$, em conjunto com idades modelo $\mathrm{T}_{\mathrm{DM}}$ entre 1,9 e 2,0 Ga e valores de $\varepsilon_{\mathrm{Nd}}(1330)$ entre $+1,8$ e $-4,3$. Também apresentaram os resultados para os plútons Porvenir, San Cristobal e Piso Firme (descritos como tardi a pós-cinemáticos) com $\mathrm{T}_{\mathrm{DM}}$ modelo ente 1,6 e $1,7 \mathrm{Ga}$ e valores de $\varepsilon_{\mathrm{Nd}}(1330)$ positivos variando entre $+2,7$ e $+1,5$ sugerindo um arco magmático intraoceânicos. Finalmente, o plúton Diamantina (tardi a pós-cinemático) apresentou idades SHRIMP em zircão de $1340 \pm$ $20 \mathrm{Ma}$ e idade modelo $\mathrm{T}_{\mathrm{DM}}$ entre 1,6 e 1,9 Ga, com valores de $\varepsilon_{\mathrm{Nd}(1330)}$ entre $+0,4$ e -1,2.

Esses resultados, segundo Matos et al. (2009) corroboram a hipótese de significativa contribuição de material juvenil mesoproterozoico durante sua gênese. Os dados junto às unidades contemporâneas na contraparte brasileira correspondem ao Granito Alto Candeias com idade de $1339 \pm 7 \mathrm{Ma}$ (MSWD 1,7) por Santos et al. (2008), reforçam a ideia de que um arco magmático juvenil mesoproterozoico finalizou a evolução acrescionária da Província Rondoniana-San Ignácio.

Bettencourt et al. (2009) reavaliaram os resultados até agora obtidos, propondo que os granitos Pensamiento, entre outras rochas que formam parte da Província Rondoniana-San Ignácio, são arcos magmáticos acrescionários gerados entre 1,56 - 1,30 Ga, relacionados ao fechamento da bacia oceânica, no final da colisão dos blocos Paraguá (Bolívia e Mato Grosso) e a Cinturão Alto Guaporé (Rondônia, Brasil), seguido por uma colisão de micro continentes entre 1340 até $1320 \mathrm{Ma}$. Contemporaneamente ao arco magmático San Ignácio, houve a formação do Complexo Colorado-Mamoré (Rizzoto \& Quadros, 2007). 


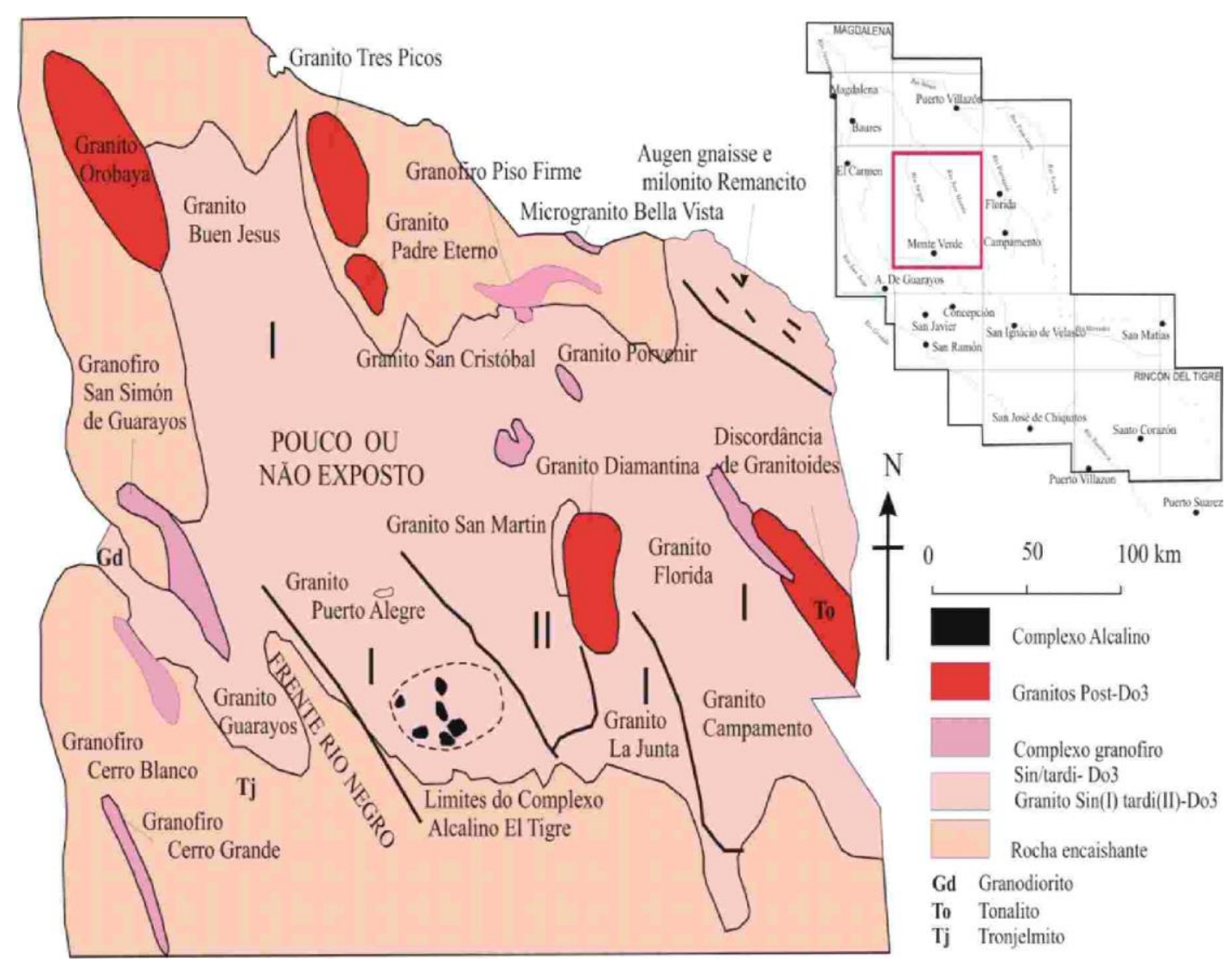

Figura 2 -Unidades do Complexo Granitoide Pensamiento, segundo Litherland et al. (1986).

\section{MATERIAIS E MÉTODOS}

Para a análise pelo método $\mathrm{U}-\mathrm{Pb}$ foi montado um epoxy com os grãos de zircão separados das rochas, posteriormente imageado por Microscópio Eletrônico de Varredura (MEV).

As imagens de catodo luminescência tiveram como objetivo mostrar a estrutura interna dos grãos de modo a observar se eles possuem um padrão de crescimento magmático ou se tem algum indício de metamorfismo (Corfu, 1988). Para a aquisição dos dados isotópicos é realizada a escolha do grão a ser analisado e o local da cratera.

O material volatilizado no zircão é transportado por gas $\mathrm{He}$, ionizado em plasma e medido em espectrômetro de massa, onde as abundancias dos isótopos de interesse ( $\mathrm{U}$, Th e $\mathrm{Pb}$ ) são medidos no Laboratório de Geocronologia da Universidade de Brasília. A correção utiliza a média dos brancos analíticos e os valores medidos do GJ1 são comparados com os valores reportados na bibliografia (Chemale et al., 2012).

A correção final foi feita com a ajuda dos diagramas de concórdia gerados no software
ISOPLOT (Ludwig, 2003).

A sistemática Sm-Nd tem se mostrado uma importante ferramenta para os estudos de evolução crustal (Sato et al. 1995), assim como também ajudando a compreender os processos geológicos além das fontes do manto superior e na crosta continental.

Doze amostras foram analisadas pela técnica de rocha total no Laboratório de Geocronologia da Universidade de Brasília. As razões isotópicas foram medidas no espectrômetro de massa multicoletor Finngan. As análises de BCR-1 produziram valores de $\mathrm{Nd}=29,44 \pm 0,70 \mathrm{ppm}$, $\mathrm{Sm}=6,77 \pm 0,21 \mathrm{ppm}, 147 \mathrm{Sm} / 144 \mathrm{Nd}=$ $0,133931 \pm 0,00071$ e $143 \mathrm{Nd} / 144 \mathrm{Nd}=$ $0,512641 \pm 0,000007$.

As idades do modelo Sm-Nd (TDM) foram calculadas de acordo com DePaolo (1988). Durante o curso dessas análises, os espaços em branco de $\mathrm{Nd}$ variaram de 100 a $50 \mathrm{pg}$. As razões Sm-Nd são corrigidas para dentro de $\pm 0,5 \% \mathrm{com}$ base em incertezas analíticas.

\section{RESULTADOS}

\section{Granodiorito Cachuela}

No extremo sul da zona de estudo, passando pela Fazenda Miraflores, encontra-se o Cerro Cachuela (Figura 3) representada por uma intrusão subcircular de $7 \mathrm{~km}$ de diâmetro. As cores da rocha variam de rosa esbranquiçada em rocha fresca a amarelada, quando alterada. Os afloramentos apresentam ora sob forma 
arredondada, com muitas fraturas ora como matacões. Apresentam foliações de 190/48 $195 / 48^{\circ}$, acompanhados de veios de quartzo paralelos a esta foliação. À medida que entramos no centro do corpo intrusivo, identificamos um aumento no tamanho da granulação, identificando-se assim cristais de feldspato potássico de até $2 \mathrm{~cm}$ de comprimento. O embasamento do Granodiorito Cachuela é apresentado por rochas graníticas integrantes do Granito San Javier, ligeiramente foliado e de granulação grossa, dificultando as vezes a distinção deste granito. Em adição, observam-se na área rochas vulcânicas como lavas, riolitos, tufos e brechas vulcanoclásticas relacionadas ao grupo Sunsás (Adamek et al., 1996).

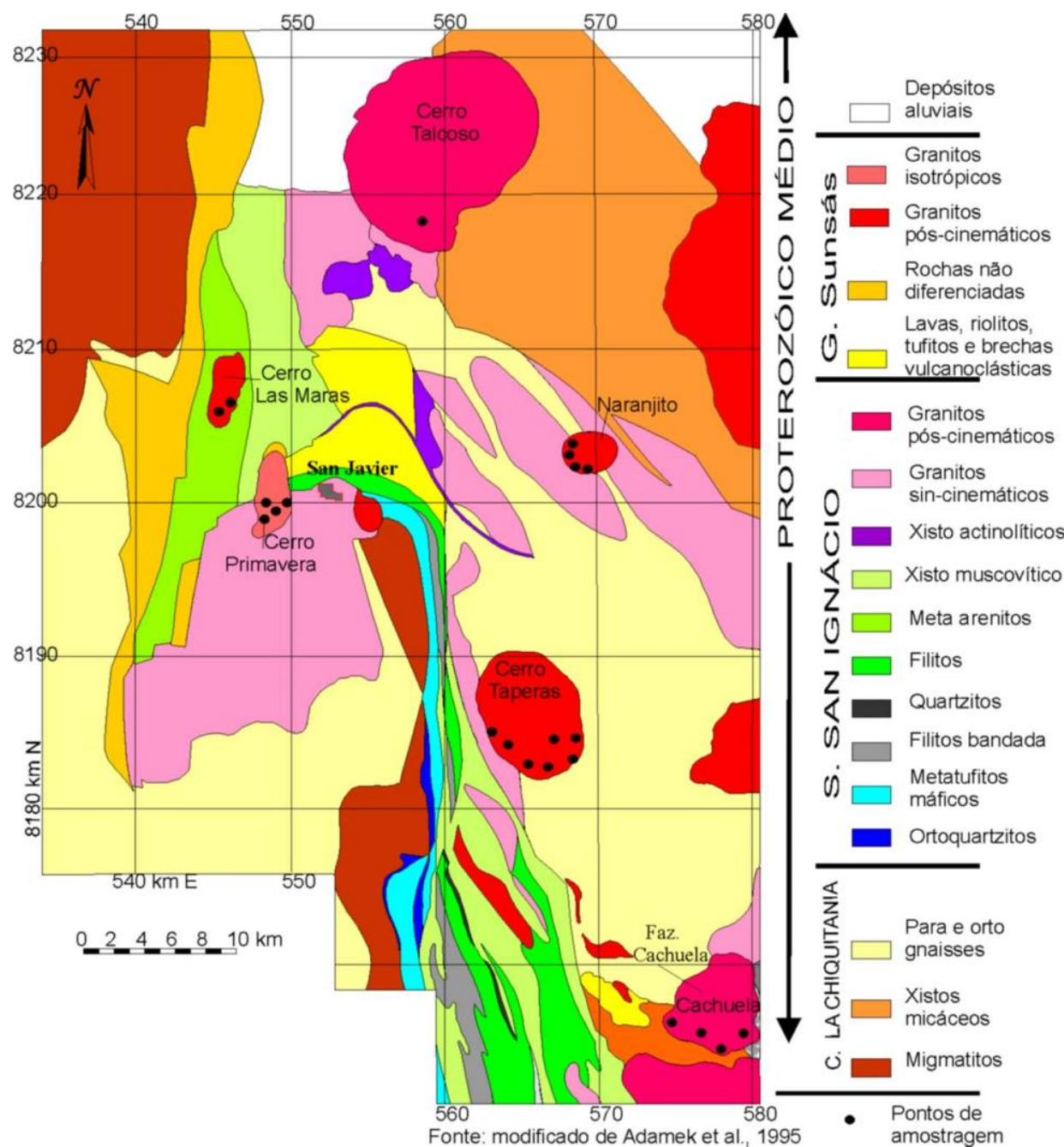

Figura 3- Mapa geológico esquemático das intrusões Talcoso, Primavera, Naranjito, Las Maras, Taperas e Cachuela. Elaborado a partir de Adamek e al. (1996).

Com base na análise semi-quantitativa (contagem pontual na lâmina) o corpo intrusivo foi classificado como monzogranito a granodiorito, sendo representado por: quartzo (40\%), feldspato potássico (20\%), plagioclásio (30\%), biotita (7\%), minerais acessórios (2\%) e minerais secundários (1\%).

O quartzo apresenta grãos anédricos com bordas suturadas e fraturas preenchidas por sericita. Os grãos de plagioclásio são subédricos de tamanho $2,5 \mathrm{~mm}$ de comprimento e com alterações de epidoto e palhetas de sericita.

Em contato com o feldspato potássico são formadas exsoluções de mimerquita, que majoritariamente rodeiam os plagioclásios. $\mathrm{O}$ microclíneo apresenta dimensão de até $7 \mathrm{~mm}$, mas em menor proporção em relação aos plagioclásios. $\mathrm{O}$ único mineral máfico reconhecido na lâmina foi a biotita tabular, pleocróica e com fraca cloritização. Alguns cristais encontram-se rodeados por minerais opacos e aparecem com inclusões de zircão.

Como minerais acessórios, ocorrem allanita de cor vermelha; zircão e titanita como inclusões nos minerais essenciais. Os minerais secundários estão representados por sericita e epidoto, como produto da alteração dos feldspatos.

\section{Sienogranito Motacusal}

$\mathrm{Na}$ direção SE de San Javier, rumo ao povoado de Santo Antonio de Lomerio (Figura 
4), observa-se o Sienogranito Motacusal, descrito por Litherland et al. (1986). As características microscópicas observadas caracterizam a rocha como sienogranito a monzogranito (Figura 4).

A mineralogia está representada por feldspatos potássicos (46\%), quartzo (25\%), plagioclásio $(14 \%)$, biotita $(12 \%)$, minerais acessórios (1\%) e minerais secundários (1\%).

O feldspato potássico é representado por microclíneo e ortoclásio, onde o primeiro predomina sendo que os grãos se caracterizam por serem fortemente fraturados e com formas subédricas. O microclíneo na maioria dos casos se encontra como fenocristais de hábitos subédri- cos, alguns deles apresentam maclas de geminação tipo Carlsbad. O quartzo ocorre em hábito anédrico, arredondado com bordas suturadas.

Os plagioclásios apresentam formas subédricas e com fraturas preenchidas por epidotos. A biotita encontra-se em duas formas. A primeira em inúmeras faixas alongadas fortemente pleocróicas, de cor marrom a marrom avermelhado, e a segunda forma em corte basal a quase hexagonal com transformações para muscovitas secundárias. A muscovita apresentase como mineral secundário em formas euédricas, mas também ocorre com formas subédricas como resultado da forte alteração do feldspato potássico e plagioclásio.

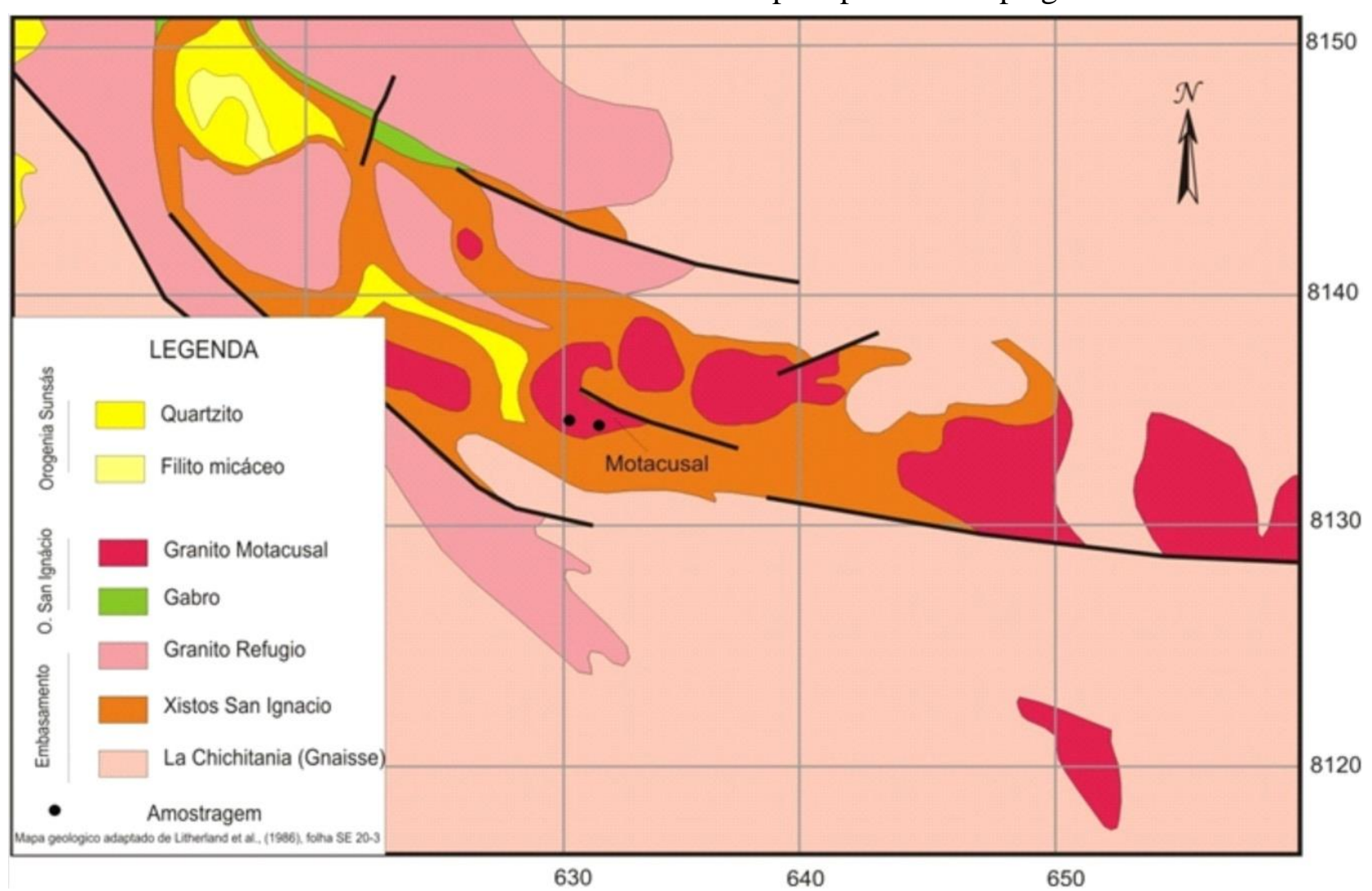

Figura 4. Mapa geológico esquemático da intrusão Sienogranítica Motacusal.

\section{Granodiorito Talcoso}

A quatro quilômetros ao norte da cidade de San Javier, aflora o Granodiorito Talcoso. Ele apresenta-se em forma circular, com $13 \mathrm{~km}$ de comprimento por $11 \mathrm{~km}$ de diâmetro e com uma suave orientação com direção NNE (Figura 5A). $\mathrm{O}$ ponto mais alto no granodiorito Talcoso é de $200 \mathrm{~m}$, sendo a intrusão mais facilmente diferenciada nas imagens de satélite (Figura $5 B)$.

O Granodiorito Talcoso, em campo, apresenta duas fácies: uma de coloração cinza clara a escura, formando uma banda contínua na margem oriental, a outra apresenta uma coloração mais escura, ocupando o resto da intrusão. A primeira fácies mostra uma granulação fina a média, enquanto a segunda fácies é de natureza mais grossa e leucocrática, de cor marrom-rosa, textura porfirítica, rica em quartzo e com fenocristais de K-feldspato até 4 $\mathrm{cm}$ de comprimento.

A composição obtida pela petrografia do Granodiorito Talcoso é marcada por uma abundância de quartzo (32\%), feldspato potássico (14\%) e plagioclásio (37\%), seguido de biotita (11\%), arfvedsonita (2\%) e minerais acessórios (1\%) e minerais secundários como sericita. 
O quartzo, mineral dominante, apresenta-se em formas de agregados anédricas, com fraturas preenchidas por sericita bordas suturadas e esporádicas inclusões de zircão. $\mathrm{O}$ plagioclásio se exibe em duas variedades: albita (An16.5) e oligoclásio (An6-5) observado com formas subédricas e macladas. A outra feição dominante que se apresenta nestes minerais é a alteração de muscovitas e epidoto. $\mathrm{O}$ feldspato potássico está representado por fenocristais de microclíneo em maior proporção, com formas quadriculadas e seus contatos com grãos de quartzo formam golfos de corrosão. A maioria dos grãos de microclíneo apresenta uma superfície de alteração argílica incipiente, junto com inclusões de palhetas de muscovita.

Os minerais máficos estão representados por biotita e arfvedsonita. Os grãos de biotita aparecem com cor castanho esverdeado, com formas tabulares e em corte basal e apresentamse acompanhados de fases acessórias com o zircão e apatita, rodeadas por minerais opacos. A hornblenda esverdeada é encontrada em menor proporção, com inclusões de zircão.

Os cristais de zircão, apatita e magnetita ocorrem como minerais acessórios, como inclusões nos cristais máficos e félsicos. Observa-se intensa sericitização do feldspato potássico e a cloritização da biotita com inclusões de zircão e constituindo halos ou auréolas de reação.

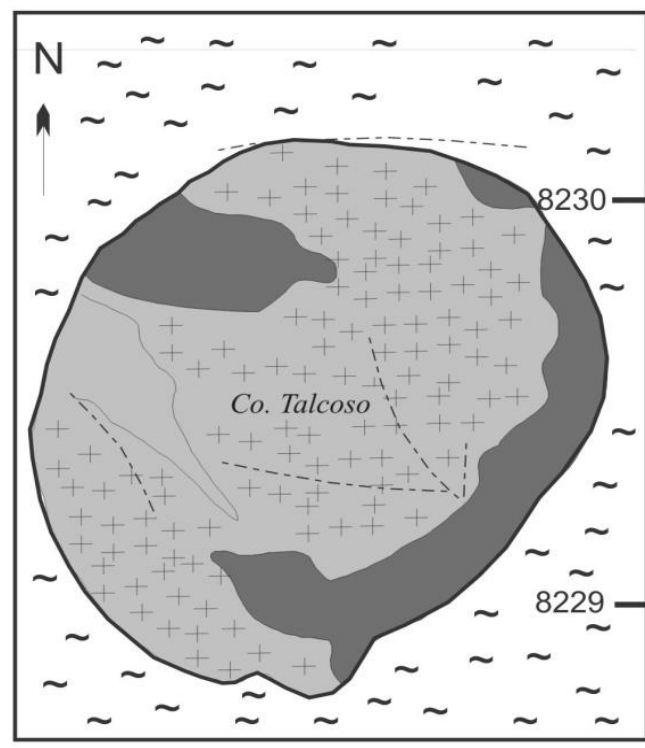

LEGENDA

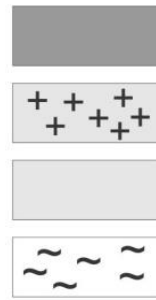

GRANITO FINO A MEDIO

GRANITO GROSSO (PORFIRÍTICO)

GRANITO GROSSO

Figura 5-A) Granodiorito Talcoso mostrando as fácies, segundo o mapeamento geológico de Fletcher (1979), a partir de imagem de satélite SPOT MS.

\section{CARACTERIZAÇÃO GEOQUÍMICA}

Foram interpretadas e analisadas sete amostras para elementos maiores, elementos traços e terras raras das rochas granitóides (Tabela 1), Talcoso (1 amostra), Cachuela (4 amostras) e Motacusal (2 amostras) para determinar as principais características químicas destes corpos graníticos. O Granodiorito Cachuela apresenta teores de $\mathrm{SiO}_{2}$ entre $70,28 \%$ até $72,79 \%$. A razão $\mathrm{K}_{2} \mathrm{O} / \mathrm{Na}_{2} \mathrm{O}$ varia de 1,43 até $1.71 \%$ ppm e o $\mathrm{Na}_{2} \mathrm{O}$ entre $3,16 \%$ até $3,57 \%$. $\mathrm{O}$ Sienogranito Motacusal apresenta teores de $\mathrm{SiO}_{2}$ entre $71,77 \%$ e $72,45 \%$ A razão $\mathrm{K}_{2} \mathrm{O} / \mathrm{Na}_{2} \mathrm{O}$ varia de 1,68 até, $1,80 \%$ ppm e o $\mathrm{Na}_{2} \mathrm{O}$ entre $3,04 \%$ e $3,06 \%$. O Granodiorito Talcoso apresenta teores de $\mathrm{SiO}_{2}$ de $75,44 \%$. A razão $\mathrm{K}_{2} \mathrm{O} / \mathrm{Na}_{2} \mathrm{O}$ é de 1,44 ppm e o $\mathrm{Na}_{2} \mathrm{O}$ é de $3,17 \%$. 
Tabela 1 - Resultados de analises litogeoquímicas das rochas do orógeno San Ignácio.

\begin{tabular}{|c|c|c|c|c|c|c|c|}
\hline \multirow[t]{2}{*}{ Elementos } & MT-05-43 & MT-05-44 & CH-07-01 & CH-07-02 & CH-07-03 & BO-04-22 & \multirow{2}{*}{$\begin{array}{c}\text { BO-04-18 } \\
\text { Talcoso }\end{array}$} \\
\hline & \multicolumn{2}{|c|}{ Motacusal } & \multicolumn{4}{|c|}{ Cachuela } & \\
\hline $\mathrm{SiO}_{2}$ & 71,77 & 72,45 & 70,28 & 72,79 & 71,96 & 72,56 & 75,44 \\
\hline $\mathrm{TiO}_{2}$ & 0,22 & 0,212 & 0,49 & 0,37 & 0,42 & 0,08 & 0,20 \\
\hline $\mathrm{Al}_{2} \mathrm{O}_{3}$ & 13,92 & 14,31 & 13,21 & 13,06 & 13,73 & 14,73 & 12,31 \\
\hline $\mathrm{Fe}_{2} \mathrm{O}_{3} *$ & 1,91 & 1,98 & 3,25 & 2,39 & 2,77 & 1,01 & 2,17 \\
\hline MnO & 0,06 & 0,051 & 0,06 & 0,05 & 0,06 & 0,02 & 0,04 \\
\hline MgO & 0,31 & 0,35 & 0,69 & 0,35 & 0,42 & 0,06 & 0,29 \\
\hline $\mathrm{CaO}$ & 0,74 & 0,8 & 1,65 & 1,23 & 1,40 & 0,60 & 1,03 \\
\hline $\mathrm{Na}_{2} \mathrm{O}$ & 3,06 & 3,04 & 3,26 & 3,16 & 3,57 & 3,39 & 3,17 \\
\hline $\mathbf{K}_{2} \mathbf{O}$ & 5,51 & 5,13 & 4,73 & 5,43 & 5,13 & 7,00 & 4,57 \\
\hline $\mathbf{P}_{2} \mathbf{O}_{5}$ & 0,08 & 0,09 & 0,14 & 0,10 & 0,13 & 0,03 & 0,06 \\
\hline LOI & 0,91 & 1,00 & 0,66 & 1,41 & 0,76 & 0,19 & 0,48 \\
\hline Total & 98,48 & 99,42 & 98,41 & 100,30 & 100,30 & 99,66 & 99,77 \\
\hline $\mathrm{K}_{2} \mathrm{O} / \mathrm{Na}_{2} \mathrm{O}$ & 1,80 & 1,68 & 1,45 & 1,71 & 1,43 & 2,06 & 1,44 \\
\hline $\mathrm{La} / \mathrm{YbN}$ & 247,85 & 183,25 & 374,64 & 388,52 & 294,74 & 105,74 & 243,06 \\
\hline $\mathrm{Ni}$ & 0,00 & 0,00 & 0,00 & 0,00 & 0,00 & 20,00 & 0,00 \\
\hline $\mathrm{Cr}$ & 0,00 & 0,00 & 0,00 & 0,00 & 0,00 & 0,00 & 30,00 \\
\hline Ba & 354,00 & 265,00 & 919,00 & 872,00 & 818,00 & 1196,00 & 529,00 \\
\hline $\mathbf{R b}$ & 490,00 & 449,00 & 225,00 & 223,00 & 221,00 & 314,00 & 260,00 \\
\hline $\mathrm{Sr}$ & 65,00 & 54,00 & 181,00 & 137,00 & 145,00 & 116,00 & 104,00 \\
\hline Th & 32,90 & 31,9 & 23,20 & 30,00 & 25,50 & 15,70 & 27,20 \\
\hline Co & 14,00 & 16,00 & 38,00 & 33,00 & 14,00 & 0,00 & 2,00 \\
\hline $\mathrm{Cu}$ & 0,00 & 10,00 & 20,00 & 0,00 & 0,00 & 0,00 & 10,00 \\
\hline Zn & 70,00 & 40,00 & 70,00 & 60,00 & 70,00 & 0,00 & 50,00 \\
\hline $\mathbf{N b}$ & 29,00 & 26,00 & 16,00 & 15,00 & 16,00 & 8,00 & 19,00 \\
\hline $\mathbf{Y}$ & 74,00 & 69,00 & 46,00 & 65,00 & 64,00 & 30,00 & 79,00 \\
\hline $\mathbf{Z r}$ & 127,00 & 131,00 & 294,00 & 228,00 & 244,00 & 58,00 & 163,00 \\
\hline Sc & 6,00 & 7,00 & 8,00 & 6,00 & 5,00 & 0,00 & 3,00 \\
\hline $\mathbf{B e}$ & 8,00 & 9,00 & 4,00 & 4,00 & 5,00 & 6,00 & 4,00 \\
\hline $\mathbf{V}$ & 19,00 & 16,00 & 43,00 & 25,00 & 21,00 & 0,00 & 14,00 \\
\hline $\mathbf{G a}$ & 23,00 & 23,00 & 20,00 & 19,00 & 21,00 & 18,00 & 18,00 \\
\hline Ge & 2,00 & 2,00 & 1,00 & 2,00 & 1,00 & 2,00 & 1,00 \\
\hline As & 0,00 & 0,00 & 0,00 & 0,00 & 0,00 & 0,00 & 0,00 \\
\hline Mo & 0,00 & 4,00 & 0,00 & 3,00 & 0,00 & 2,00 & 3,00 \\
\hline $\mathbf{A g}$ & 0,00 & 0,00 & 0,00 & 0,00 & 0,00 & 0,00 & 0,00 \\
\hline In & 0,00 & 0,00 & 0,00 & 0,00 & 0,00 & 0,00 & 0,00 \\
\hline Sn & 14,00 & 12,00 & 5,00 & 5,00 & 5,00 & 2,00 & 32,00 \\
\hline Sb & 2,00 & 0,00 & 1,10 & 0,50 & 0,00 & 1,10 & 1,00 \\
\hline Cs & 28,60 & 22,5 & 2,20 & 1,60 & 2,30 & 1,90 & 4,60 \\
\hline Hf & 5,00 & 4,6 & 9,00 & 7,30 & 7,90 & 3,30 & 5,50 \\
\hline $\mathbf{T a}$ & 4,20 & 4,1 & 1,50 & 2,00 & 1,70 & 1,30 & 1,70 \\
\hline $\mathbf{W}$ & 168,00 & 176,00 & 413,00 & 381,00 & 143,00 & 0,00 & 0,00 \\
\hline TI & 2,40 & 1,4 & 1,20 & 1,20 & 1,00 & 1,50 & 1,30 \\
\hline $\mathbf{P b}$ & 35,00 & 20,00 & 25,00 & 26,00 & 23,00 & 24,00 & 26,00 \\
\hline $\mathbf{B i}$ & $<0,4$ & $<0,4$ & $<0,4$ & $<0,4$ & $<0,4$ & $<0,4$ & $<0,4$ \\
\hline $\mathbf{U}$ & 18,20 & 12,8 & 5,40 & 6,60 & 3,50 & 3,70 & 5,50 \\
\hline La & 51,80 & 38,3 & 78,30 & 81,20 & 61,60 & 50,60 & 50,80 \\
\hline $\mathrm{Ce}$ & 92,20 & 79,3 & 152,00 & 130,00 & 109,00 & 47,30 & 104,00 \\
\hline Pr & 12,80 & 9,85 & 17,40 & 18,70 & 13,70 & 9,92 & 11,70 \\
\hline Nd & 45,60 & 35,5 & 54,70 & 60,10 & 45,20 & 29,50 & 44,60 \\
\hline Sm & 10,00 & 7,9 & 9,50 & 11,00 & 8,70 & 5,10 & 10,00 \\
\hline Eu & 1,00 & 0,65 & 1,38 & 1,59 & 1,60 & 1,81 & 0,82 \\
\hline Gd & 10,80 & 8,6 & 7,90 & 10,20 & 8,60 & 4,80 & 9,50 \\
\hline $\mathbf{T b}$ & 2,10 & 1,7 & 1,40 & 1,80 & 1,60 & 0,70 & 1,70 \\
\hline Dy & 11,80 & 10,3 & 7,90 & 10,20 & 8,90 & 3,90 & 10,60 \\
\hline Ho & 2,20 & 2,00 & 1,50 & 2,10 & 1,80 & 0,80 & 2,30 \\
\hline Er & 6,90 & 6,3 & 5,00 & 6,70 & 5,90 & 2,90 & 7,80 \\
\hline $\mathbf{T m}$ & 1,11 & 0,98 & 0,82 & 1,08 & 0,95 & 0,53 & 1,31 \\
\hline $\mathbf{Y b}$ & 6,80 & 6,3 & 5,40 & 6,80 & 6,10 & 4,10 & 8,20 \\
\hline Lu & 0,96 & 0,9 & 0,81 & 0,99 & 0,94 & 0,75 & 1,23 \\
\hline
\end{tabular}

O diagrama da figura 6A de De La Roche et al. (1980) e Le Maitre (1989) utilizado para rochas plutônicas classifica a estes granitóides entre granito a granodiorito.

O diagrama de classificação TAS segundo De La Roche et al., (1980) para rochas da unidade San Ignácio é apresentado na figura 6A. No diagrama da figura $6 \mathrm{~B} \quad\left(\mathrm{Al}_{2} \mathrm{O}_{3} / \mathrm{Na}_{2} \mathrm{O}+\mathrm{K}_{2} \mathrm{O}\right)$ versus $\mathrm{Al}_{2} \mathrm{O}_{3}\left(\mathrm{CaO}+\mathrm{Na}_{2} \mathrm{O}+\mathrm{K}_{2} \mathrm{O}\right)$ de Maniar \& Picoli (1989) se observa que as rochas dos granitoides Talcoso e Motacusal encontram-se no campo peraluminoso e o Granodiorito Cachuela foi caracterizado como peraluminoso a levemente metaluminoso. As amostras das 
rochas San Ignácio foram caracterizadas como uma série de médio $\mathrm{K}$ na maioria dos casos até alto K (Figura 6C), em função da concentração de potássio segundo Lê Maitre, (1989).

Com o objetivo de definir o ambiente tectônico onde foram gerados os resultados geoquímicos das intrusões Talcoso, Motacusal e Cachuela foram lançados nos diagramas tectônicos, $\mathrm{Rb}$ vs $\mathrm{Y}+\mathrm{Nb}$ e $\mathrm{Nb}$ vs $\mathrm{Y}$ (Figuras 6D e 6E), de Pearce et al. (1984). Estes diagramas mostram que as amostras das intrusões Motacusal e Cachuela encontram-se no campo Intraplaca (segundo a proposta de Chappel \& White, 2001).

As amostras que caíram no ambiente intraplaca segundo Pearce et al. (1984), foram direcionadas ao uso da hipótese proposta por Eby (1992), no qual o autor sugere que os granitóides lançados no ambiente intraplaca podem ser de Tipo A (Figura 6F). Com esses critérios, mais os elementos incompatíveis $\mathrm{Ce}, \mathrm{Y}, \mathrm{Nb}, \mathrm{Ga}$ e $\mathrm{Al}$ é possível identificar que as rochas das intrusões Motacusal e Cachuela são Tipo A2.

Os resultados analíticos para os Elementos Terras Raras (ETR) das amostras estudadas, foram utilizados para a construção dos diagramas da figura 7. As amostras do Granodiorito Cachuela apresentam um padrão de forte fracionamento dos ETRL leves e na porção de ETR pesados apresentam uma tendência horizontalizada, junto com uma anomalia negativa de Eu (Figura 7A), provavelmente devido à presença de plagioclásios na fase inicial de cristalização. A amostra BO-04-22 apresenta uma anomalia de Ce positiva e o padrão dos ETRP é horizontalizado.

Para o Sienogranito Motacusal (Figura 7C), existe a mesma tendência horizontalizada tanto para os ETRL como para os ETRP, mas uma marcada anomalia negativa de Eu. E para o Granodiorito Talcoso o comportamento dos ETRL e a porção das ETRP. Padrão semelhante as duas amostras já citadas (Figura 7E). As razões $\mathrm{La} / \mathrm{Yb}$ das amostras dos granitos da Suíte San Ignácio apresentam valores entre 388,52 e 242,06 , indicando alto fracionamento entre os ETR leves e os pesados. As razões $\mathrm{Eu} / \mathrm{Eu}^{*}$ variam entre 8,34 a 21,76 e sugerem a participação do plagioclásio na assembleia de minerais durante a cristalização e fracionamento do magma gerador das rochas desta suíte.

As construções dos diagramas da figuras 7B, $\mathrm{D}$ e $\mathrm{F}$, levaram em conta os dados geoquímicos dos granitóides San Ignácio e os exemplos encontrados na literatura descrita por Pearce et al., (1984). Nesse sentido, os dados foram normalizados pelos valores ORG e indicam que o Granodiorito Cachuela foi gerado em um ambiente de intraplaca similar aos granitos intraplaca da Islândia (Figura 7B); enquanto que o Sienogranito Motacusal apresenta feições similares à os granitos gerados num ambiente sin-colisional (Figura 7D) e o Granodiorito Talcoso provavelmente é formado num ambiente sin colisionais formados no Gabug, Tibet (Figura $7 \mathrm{~F})$.

\section{CARACTERIZAÇÃO ISOTÓPICA U/Pb}

Os resultados U-Pb para os grãos de zircão do Granodiorito Cachuela são representados por seis pontos (Tabela 2) lançados no diagrama da concórdia apresentando um intercepto superior a $1307 \pm 7$ Ma e um intercepto inferior de $150 \pm$ $215 \mathrm{Ma}$, como pode ser observado na figura 8A.

Os grãos de zircão das amostras do Sienogranito Motacusal, na lupa apresentam-se com uma coloração amarela até variações avermelhadas, conforme visualizados na figura 8B. No imageamento do backscattered (MEV) da figura 8B observa-se duas formas subédricas até anédricas; a primeira, numa relação $3: 1$, sendo a maioria dos grãos, e a segunda $2: 2 \mathrm{em}$ menor proporção. Nesta imagem também são visualizadas as fraturas nos grãos, zonações em alguns cristais, sobrecrescimento e inclusões de monazita (Figura 8B). Para o Sienogranito
Motacusal obteve-se a idade de $1330 \pm 36 \mathrm{Ma}$ (n $=10$; Figura $8 \mathrm{C}$ ). Este valor é interpretado como idade de cristalização uma vez que as razões U/Th entre 0,02 e 0,30 indicam uma maioria de zircões magmáticos (resultados apresentados na tabela 3.

Os grãos de zircão do Granodiorito Talcoso apresentam formas bipiramidais, translúcidos e com uma coloração rosa pálido na lupa, conforme observado na fotografia da figura 8C. Já no imageamento MEV da figura $8 \mathrm{c}$, observam-se as zonações reveladas pelas fraturas radiais, formas subédricas, e inclusões de tório, urânio, monazita, apatita e xenotímio. O diagrama concórdia apresentou uma idade de $1333 \pm 68$ Ma com oito análises pontuais (Figura $8 \mathrm{C})$, com razões $\mathrm{Th} / \mathrm{U}$ que variam de 0.18 até 0.27 (Tabela 4). 

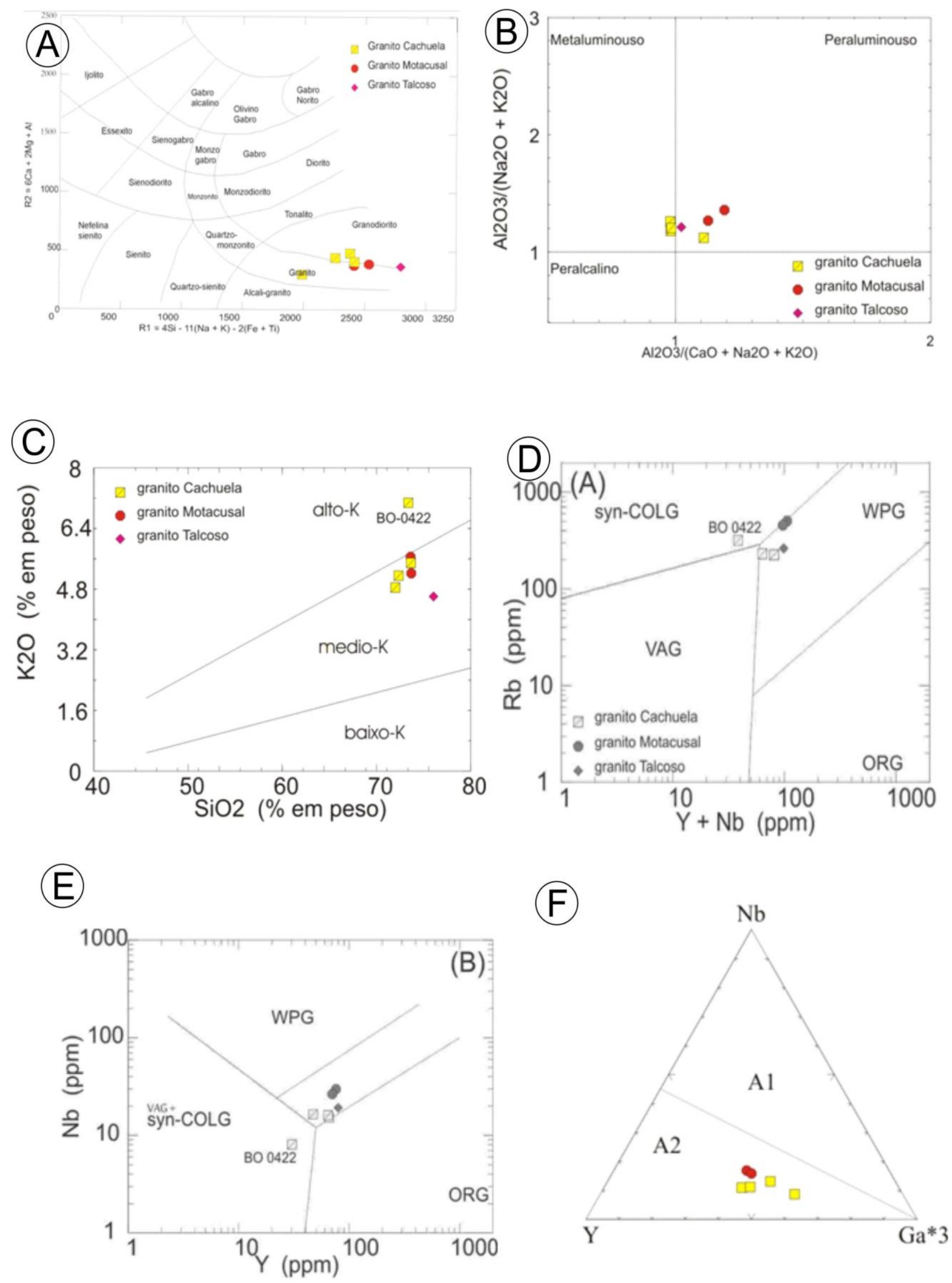

Figura 6 - A) Diagrama de classificação TAS segundo De La Roche et al., (1980) para rochas da unidade San Ignácio. B) Índice de saturação de alumina $\mathrm{Al}_{2} \mathrm{O}_{3} /\left(\mathrm{Na}_{2} \mathrm{O}+\mathrm{K}_{2} \mathrm{O}\right)$ versus $\mathrm{Al}_{2} \mathrm{O}_{3}\left(\mathrm{CaO}+\mathrm{Na}_{2} \mathrm{O}+\mathrm{K}_{2} \mathrm{O}\right.$, segundo Maniar \& Picoli (1989), para as rochas da unidade San Ignácio. C) Diagrama de classificação de séries magmáticas com base na saturação em potássio, segundo Lê Maitre (1989). D) Diagrama ternários em função de Nb, Y e $3 *$ Ga para distinguir os granitos Tipo A1 e A2 segundo Eby (1990), para os granitóides estudados. E e F) Diagramas de discriminação tectônica Rb vs. Y+ Nb e Nb vs Y, propostos por Pearce et al., (1984) onde (VAG) são granitos de arco vulcânico, (Syn-COLG) são granitos colisionais (Tipo-S); (WPG) são granitos de intraplaca (tipo-A) e (ORG) são granitos de cordilheira oceânica o plagiogranitos. 

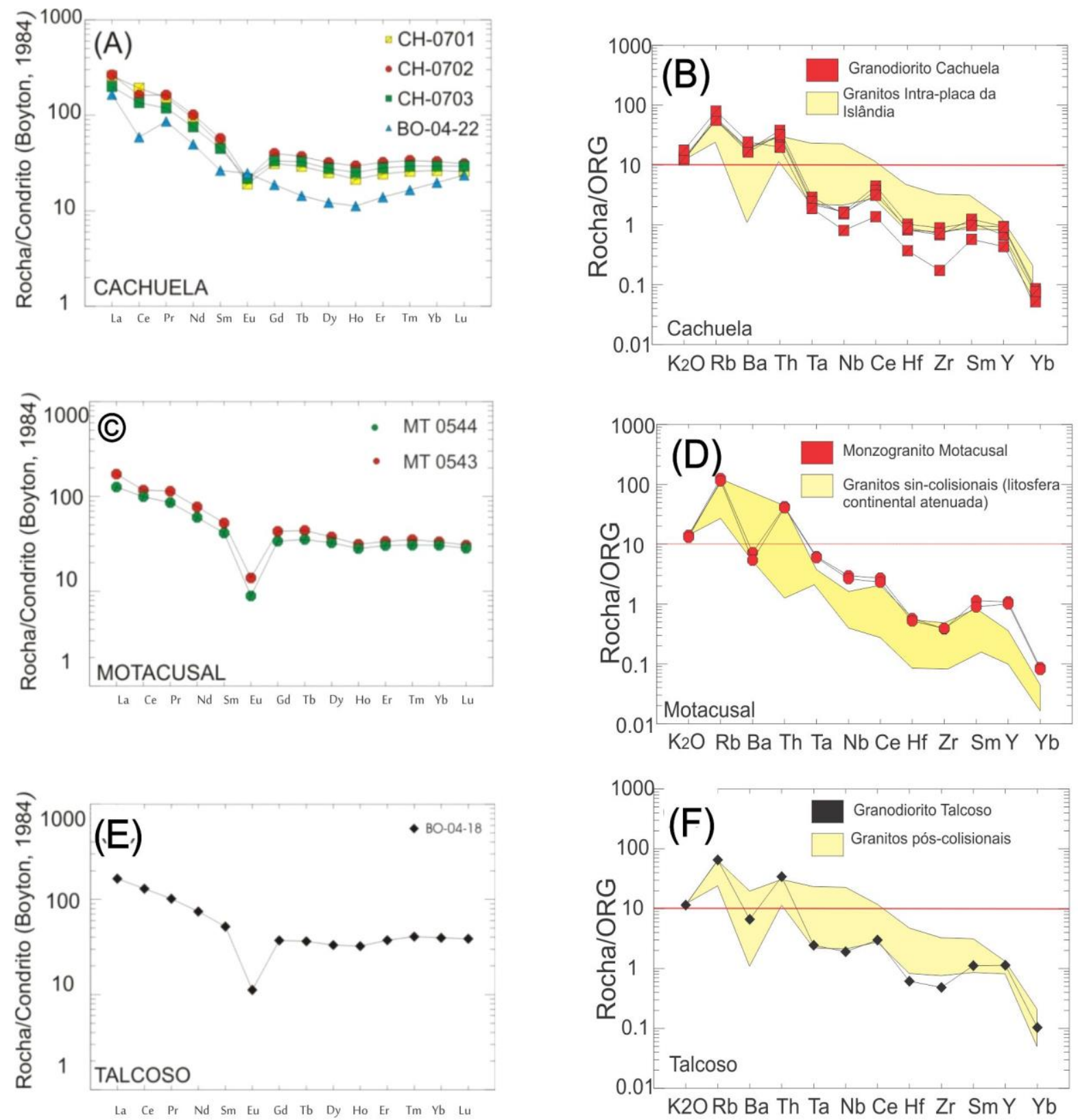

Figura 7 - A) Padrão de Terras Raras dos granitóides San Ignácio do Pré- Cambriano Boliviano, normalizado pelo Condrito, segundo Boynton (1984). B)Elementos traços normalizados pelo ORG nos granitóides Cachuela, El, Motacusal e Talcoso.

Tabela 2 - Dados isotópicos U-Pb (TIMS) em zircões do Granodiorito Cachuela.

\begin{tabular}{|c|c|c|c|c|c|c|c|c|}
\hline \multirow{2}{*}{$\begin{array}{c}\text { BO0422 } \\
\text { Fração }\end{array}$} & \multicolumn{6}{|c|}{ RAZÕES ISOTÓPICAS } & \multicolumn{2}{|c|}{$\begin{array}{c}\text { IDADES } \\
\text { APARENTES(Ma) }\end{array}$} \\
\hline & $\mathbf{U}$ & $\mathbf{P b}$ & $\stackrel{{ }^{206} \mathrm{~Pb}}{\longrightarrow}$ & ${ }^{208} \mathbf{P b}$ & ${ }^{206} \mathrm{~Pb}^{*}$ & error & ${ }^{207} \mathbf{P b}^{*}$ & ${ }^{207} \mathrm{~Pb}^{*}$ \\
\hline & $(\mathbf{p p m})$ & $(\mathbf{p p m})$ & ${ }^{204} \mathrm{~Pb}$ & ${ }^{206} \mathrm{~Pb}$ & ${ }^{238} \mathbf{U}^{*}$ & & ${ }^{235} \mathbf{U}^{*}$ & ${ }^{206} \mathrm{~Pb}^{*}$ \\
\hline $\mathbf{Z 1}$ & 94.86 & 23.45 & 506.23 & 0.286 & 0.20948 & 0.79 & 2.43621 & 0.08435 \\
\hline $\mathbf{Z 2}$ & 196.59 & 48.06 & 678.44 & 0.236 & 0.21088 & 1.12 & 2.44958 & 0.08425 \\
\hline $\mathbf{Z 3}$ & 128.50 & 32.59 & 478.22 & 0.277 & 0.21149 & 1.76 & 2.47111 & 0.08474 \\
\hline $\mathbf{Z 4}$ & 383.88 & 97.88 & 1988.46 & 0.282 & 0.21671 & 0.27 & 2.52696 & 0.08457 \\
\hline $\mathbf{Z 5}$ & 173.57 & 48.98 & 690.33 & 0.358 & 0.22408 & 1.15 & 2.61792 & 0.08473 \\
\hline Z6 & 333.13 & 85.96 & 1110.97 & 0.221 & 0.22616 & 0.21 & 2.63673 & 0.08456 \\
\hline
\end{tabular}


Tabela 3 - Dados isotópicos U-Pb por ICPMS-LA em zircões do Sienogranito Motacusal.

\begin{tabular}{|c|c|c|c|c|c|c|c|c|c|c|c|c|c|c|c|}
\hline PEMT054 & & & \multicolumn{4}{|c|}{ RAZÕES ISOTÓPICAS } & & & & & & \multicolumn{4}{|c|}{ IDADE APARENTE (Ma) } \\
\hline Fração & & ${ }^{206} \mathrm{~Pb}$ & ${ }^{207} \mathbf{P b}$ & & $207 \mathrm{~Pb}$ & $1 \mathrm{~s}(\%$ & $206 \mathrm{~Pb}$ & & & ${ }^{207} \mathrm{~Pb}$ & & ${ }^{207} \mathrm{~Pb}$ & & $206 \mathrm{~Pb}$ & \\
\hline & $\mathbf{T h} / \mathrm{U}$ & ${ }^{204} \mathrm{~Pb}$ & ${ }^{206} \mathrm{~Pb}$ & $\begin{array}{c}1 \mathrm{~s} \\
(\%)\end{array}$ & ${ }^{235} \mathbf{P b}$ & & ${ }^{238} \mathbf{U}$ & $\begin{array}{c}15 \\
(\%)\end{array}$ & Rho & ${ }^{206} \mathrm{~Pb}$ & $\begin{array}{l}1 s \\
(\%\end{array}$ & ${ }^{205} \mathrm{~Pb}$ & $\begin{array}{l}1 \mathrm{1s} \\
(\%\end{array}$ & ${ }^{238} \mathrm{U}$ & $\begin{array}{l}1 \mathrm{1s} \\
(\%\end{array}$ \\
\hline $04 Z 2$ & 0,14 & 10526 & 0,08136 & 1,6 & 2,8210 & 5,5 & 0,25147 & 5,3 & 0,96 & 1230,2 & 30,5 & 1361,1 & 40,4 & 1446,1 & 67,9 \\
\hline 05Z03B & 0,13 & 6352 & 0,10907 & 0,6 & 2,7127 & 1,9 & 0,18038 & 1,8 & 0,93 & 1783,9 & 11,3 & 1331,9 & 14,0 & 1069,1 & 17,6 \\
\hline $06 z 03 N$ & 0,37 & 48733 & 0,11162 & 0,8 & 5,6655 & 1,7 & 0,36812 & 1,5 & 0,91 & 1826,0 & 14,9 & 1926,1 & 14,3 & 2020,5 & 25,1 \\
\hline $09 z 4 N$ & 0,21 & 1537 & 0,09506 & 0,9 & 1,1083 & 2,4 & 0,08456 & 2,2 & 0,92 & 1529,3 & 16,8 & 757,4 & 12,6 & 523,3 & 11,0 \\
\hline $015 z 7$ & 0,24 & 884 & 0,10915 & 1,1 & 4,0053 & 2,8 & 0,26614 & 2,6 & 0,91 & 1785,3 & 19,3 & 1635,3 & 22,4 & 1521,2 & 34,8 \\
\hline 018z09B & 0,06 & 3082 & 0,07868 & 2,8 & 1,8515 & 3,2 & 0,17066 & 1,6 & 0,70 & 1164,2 & 53,8 & 1064,0 & 20,9 & 1015,8 & 15,3 \\
\hline $027 \mathrm{z} 12$ & 0,31 & 16646 & 0,11603 & 0,7 & 6,0515 & 2,3 & 0,37827 & 2,2 & 0,94 & 1895,9 & 12,5 & 1983,3 & 20,1 & 2068,2 & 39,1 \\
\hline $028 Z 13$ & 0,16 & 96917 & 0,08825 & 0,5 & 3,0709 & 1,8 & 0,25238 & 1,7 & 0,95 & 1387,9 & 8,6 & 1425,5 & 13,4 & 1450,7 & 22,0 \\
\hline 029Z014b & 0,02 & 2525 & 0,08985 & 2,8 & 0,4291 & 4,1 & 0,03463 & 3,0 & 0,71 & 1422,4 & 53,2 & 362,5 & 12,5 & 219,5 & 6,4 \\
\hline 030z014N & 0,10 & 1182 & 0,10042 & 1,2 & 1,2639 & 3,8 & 0,09128 & 3,6 & 0,98 & 1631,9 & 21,9 & 829,6 & 21,2 & 563,1 & 19,3 \\
\hline $045 \mathrm{z} 20$ & 0,17 & 4585 & 0,08500 & 2,0 & 0,9111 & 5,0 & 0,07774 & 4,6 & 0,92 & 1315,5 & 37,7 & 657,6 & 24,1 & 482,6 & 21,5 \\
\hline $046 z 21$ & 0,28 & 18560 & 0,17553 & 0,6 & 11,7581 & 1,9 & 0,48584 & 1,8 & 0,93 & 2611,0 & 10,3 & 2585,3 & 17,9 & 2552,6 & 38,3 \\
\hline $047 Z 022$ & 0,12 & 737 & 0,09061 & 0,8 & 0,6503 & 2,1 & 0,05206 & 2,0 & 0,92 & 1438,4 & 14,8 & 508,7 & 8,4 & 327,1 & 6,3 \\
\hline $048 z 023$ & 0,15 & 56156 & 0,07381 & 0,8 & 1,4120 & 2,0 & 0,13874 & 1,9 & 0,96 & 1036,4 & 15,4 & 894,0 & 12,0 & 837,5 & 14,8 \\
\hline $051 z 24$ & 0,15 & 49973 & 0,07923 & 0,5 & 2,1474 & 1,4 & 0,19658 & 1,3 & 0,89 & 1177,8 & 10,2 & 1164,2 & 9,9 & 1156,9 & 14,2 \\
\hline $052 \mathrm{z} 25$ & 0,40 & 64137 & 0,10375 & 0,5 & 4,1162 & 1,4 & 0,28775 & 1,3 & 0,88 & 1692,3 & 9,6 & 1657,5 & 11,1 & 1630,3 & 18,1 \\
\hline
\end{tabular}

Tabela 4 - Dados isotópicos U-Pb por ICPMS-LA em zircões do Granodiorito Talcoso

\begin{tabular}{|c|c|c|c|c|c|c|c|c|c|c|c|c|c|c|c|}
\hline B00418 & & & & & ZŌES ISO & OPIC & $\overline{\mathrm{AS}}$ & & & & & $\overline{D E} \mathrm{AP}$ & RENTI & (Ma) & \\
\hline & & ${ }^{206} \mathrm{~Pb}$ & ${ }^{207} \mathrm{~Pb}$ & & ${ }^{207} \mathrm{~Pb}$ & & ${ }^{206} \mathrm{~Pb}$ & & & ${ }^{207} \mathrm{~Pb}$ & & ${ }^{207} \mathrm{~Pb}$ & & $206 \mathrm{~Pb}$ & \\
\hline Fração & Th/U & ${ }^{204} \mathrm{~Pb}$ & ${ }^{206} \mathrm{~Pb}$ & $\begin{array}{c}\text { 1s } \\
\text { (\%) }\end{array}$ & ${ }^{235} \mathrm{~Pb}$ & $\begin{array}{c}1 s \\
(\%)\end{array}$ & $238 \mathrm{U}$ & $\begin{array}{c}15 \\
(\%)\end{array}$ & Rho & ${ }^{206} \mathrm{~Pb}$ & $\begin{array}{c}\text { 1s } \\
\text { (\%) }\end{array}$ & ${ }^{05} \mathrm{~Pb}$ & $\begin{array}{c}1 s \\
(\%)\end{array}$ & $238 \mathrm{U}$ & $\begin{array}{l}15 \\
(\%)\end{array}$ \\
\hline $03 Z 1$ & 0,23 & 1334 & $p, 13303$ & 5,8 & 4,4052 & 6,2 & 0,24017 & 2,3 & 0,34 & 2138,4 & 97,8 & 1713,3 & 50,2 & 1387,6 & 28,5 \\
\hline $04 Z 2$ & 0,17 & 11588 & 0,08773 & 1,3 & 3,0304 & 2,1 & 0,25052 & 1,7 & 0,76 & 1376,7 & 24,0 & 1415,3 & 16,2 & 1441,1 & 22,3 \\
\hline $06 z 04$ & 0,21 & 4551 & p,10226 & 2,7 & 3,34 & 3,0 & 0,23 & 1,4 & 0,61 & 1665,6 & 48,8 & 1490,9 & 23,3 & & 16,9 \\
\hline 0975 & 0,23 & 6954 & $p, 08207$ & 1,4 & 2,6611 & 2,5 & 0,23515 & 2,2 & 0,83 & 1247,3 & 26,4 & 1317,7 & 18,6 & & 26,3 \\
\hline $010 Z 6.1$ & 0,39 & 7 & 0,31310 & 2,9 & 13,9406 & 3,8 & 0,32292 & 2,5 & 0,63 & 3536,3 & 44,4 & 2745,7 & 35,7 & & 38,8 \\
\hline $11 Z 06.2$ & 0,27 & 184 & $p, 22229$ & 2,6 & 5,8954 & 3,5 & 0,19235 & 2,3 & 0,64 & 2997,4 & 41,6 & 1960,6 & 29,9 & 1134,1 & 23,9 \\
\hline $012 z 07$ & 0,23 & 811 & p,09925 & 3,4 & 2,9733 & 3,8 & 0,21727 & 1,7 & 0,66 & 1610,1 & 61,6 & 1400,8 & 28,4 & & 19,8 \\
\hline $010 Z 6.1$ & 0,07 & 145 & $p, 10841$ & 2,2 & 2,1870 & 6,6 & 0,14630 & 6,2 & 0,94 & 1772,9 & 39,9 & 1176,9 & 45,2 & & 51,2 \\
\hline $17 Z 10.1$ & 0,17 & 12857 & $\mathrm{p}, 08291$ & 1,0 & 2,8740 & 1,8 & 0,25141 & 1,5 & 0,77 & 1267,1 & 19,2 & 1375,1 & 13,2 & & 18,8 \\
\hline $018 z 10.2$ & 0,17 & 54 & 0,50659 & 6,0 & 20,2804 & 6,2 & 0,29035 & 1,7 & 0,43 & 4260,5 & 85,5 & 3104,8 & 58,5 & 1643,3 & 24,4 \\
\hline $021 Z 11$ & 0,23 & 47041 & p,07747 & 3,4 & 2,5070 & 3,6 & 0,23470 & 1,2 & 0,26 & 1133,4 & 66,5 & 1274,1 & 25,8 & 1359,1 & 14,3 \\
\hline $022 Z 12$ & 0,17 & 799250 & 0,58531 & 26,5 & 140,7931 & 37,5 & 1,74460 & 26,6 & 0,71 & 4471,9 & 339,1 & 5030,6 & 321,6 & & 1006,5 \\
\hline $023 Z 13$ & 0,25 & 1027 & $p, 08608$ & 3,2 & 3,0936 & 4,2 & 0,26067 & 2,7 & 0,62 & 1339,9 & 60,6 & & 31,4 & & 35,3 \\
\hline $028 Z 14 N$ & 0,28 & 872 & 0,10507 & 2,0 & 3,0023 & 3,0 & 0,20724 & 2,2 & 0,73 & 1715,5 & 36,1 & 1408,2 & 22,3 & 1214,1 & 24,3 \\
\hline $035 Z 16$ & 0,26 & 2054 & 0,10651 & 1,3 & 3,0796 & 2,1 & 0,20971 & 1,6 & 0,67 & 1740,5 & 23,6 & 1427,6 & 15,7 & 1227,2 & 17,9 \\
\hline $036 Z 17$ & 0,28 & 97321 & 0,08205 & 0,6 & 2,5195 & 1,8 & 0,22271 & 1,7 & 0,92 & 1246,7 & 11,6 & 1277,7 & 13,1 & 1296,2 & 20,1 \\
\hline $041 Z 20$ & 0,32 & 1045 & 0,09625 & 1,2 & 2,3131 & 1,9 & 0,17430 & 1,5 & 0,72 & 1552,7 & 22,2 & 1216,3 & 13,4 & 1035,7 & 14,3 \\
\hline $042 Z 21$ & 0,22 & 17 & 0,19035 & 3,8 & 3,0911 & 4,1 & 0,11778 & 1,7 & 0,38 & 2745,2 & 60,4 & 1430,5 & 31,2 & 717,8 & 11,8 \\
\hline $047 Z 24$ & 0,21 & 949 & $p, 10179$ & 1,2 & 3,0977 & 2,1 & 0,22071 & 1,8 & 0,82 & 1657,1 & 21,3 & 1432,1 & 16,4 & 1285,6 & 21,1 \\
\hline $048 Z 25$ & 0,21 & 56915 & $p, 07968$ & 0,6 & 2,1840 & 2,0 & & 1,9 & 0,95 & 1189,1 & 11,1 & 1175,9 & 13,6 & 1168,8 & 20,1 \\
\hline
\end{tabular}



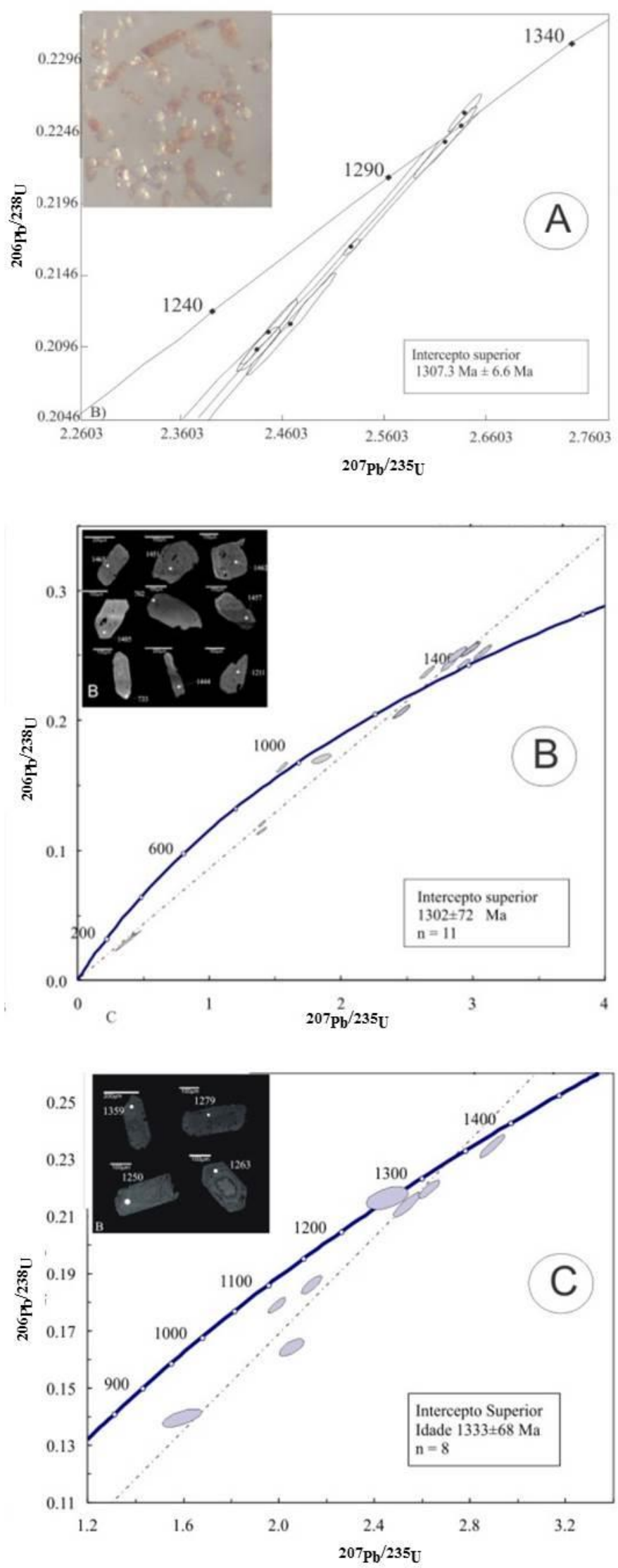

Figura 8 - A) Diagrama da concórdia para seis grãos de zircão, o intercepto superior indica uma idade de $1307 \pm 6.6 \mathrm{Ma}$ e o intercepto inferior $149.8 \pm 214$ Ma. Imagem dos grãos de zircão da amostra BO-04-22 (Granodiorito Cachuela) mostrando as duas formas presentes (alongada e subarredondado), assim como também a coloração avermelhada. B) Diagrama da concórdia para oito zircões, o intercepto superior indica uma idade $1333 \pm 68 \mathrm{Ma}$. Imagem dos grãos de zircão da amostra Sienogranito Motacusal são apresentadas no canto superior esquerdo do diagrama. C) Diagrama da concórdia para 10 grãos de zircão, o intercepto superior indica uma idade $1330 \pm 36$ Ma. Imagem dos grãos de zircão do Granodiorito Talcoso. 


\section{EVOLUÇÃO ISOTÓPICA DO Nd DO PRECAMBRIANO BOLIVIANO}

As amostras Sm-Nd em rocha total para o Granodiorito Cachuela apresentam razões de $f_{\mathrm{Sm} / \mathrm{Nd}}-0.46$ até 0.48 (Tabela 5) a idade modelo $\mathrm{T}_{\mathrm{DM}}$ é $1,76 \mathrm{Ga}$ e o $\varepsilon_{\mathrm{Nd}(1334)}$ entre -0.77 até $-0,96$. A amostra sienogranítica da intrusão Motacusal apresenta valor de $f_{\mathrm{Sm} / \mathrm{Nd}}=-0.28$, idade modelo $\mathrm{T}_{\mathrm{DM}}=2,30$ Ga e o $\varepsilon_{\mathrm{Nd}}$ (a 1330) de-3.83.

Para o Granodiorito Talcoso os resultados isotópicos $\mathrm{Sm}-\mathrm{Nd}$ indicam uma idade modelo $\mathrm{T}_{\mathrm{DM}}=1,97 \mathrm{Ga}$ e $\varepsilon_{\mathrm{Nd}}(1340)-2,13$ e razão $f_{\mathrm{Sm} / \mathrm{Nd}}-$ 0.35. Os dados Sm-Nd obtidos para as unidades graníticas do evento San Ignácio (Tabela 5) indicam fontes mantélicas e crustais. As amostras aqui estudadas (Cachuela, Motacusal e Talcoso) apresentam valores de $\mathrm{T}_{\mathrm{DM}}$ entre 1,73 e $2,30 \mathrm{Ga}$ e valores de $\varepsilon_{\mathrm{Nd}}(1330)$ entre $-0,77$ e $-3,86$ e podem indicar que as fontes das rochas do magmatismo San Ignácio foram formadas por material derivado do manto com contaminação crustal. Estes resultados também podem sugerir que os granitóides Cachuela, Motacusal e Talcoso apresentam contaminação do embasamento Lomas Manechis. Em adição, Matos et al. (2009) reportou dados $\mathrm{Sm}-\mathrm{Nd}$ para os granitos San Martin, La Junta, Diamantina Porvenir, San Cristobal e Piso Firme (Figura 9).

Os autores dividiram estas unidades em função das feições tectônicas, propondo granitos formados em ambiente sin-tectônicos e póstectônicos.

Tabela 5 - Resultados Sm-Nd das rochas do orógeno San Ignácio.

\begin{tabular}{c|c|c|c|c|c|c|c|c|c}
\hline AMOSTRA & UNIDADE & $\begin{array}{c}\text { Sm } \\
(\mathbf{p p m})\end{array}$ & $\begin{array}{c}\mathbf{N d} \\
(\mathbf{p p m})\end{array}$ & $\begin{array}{c}\mathbf{1 4}^{\mathbf{1 4 4}} \mathbf{S m} \\
\mathbf{1 4}\end{array}$ & $\begin{array}{c}{ }^{\mathbf{1 4 3}} \mathbf{N d} \\
{ }^{\mathbf{1 4 4}} \mathbf{N d}\end{array}$ & $\mathbf{N d}(\mathbf{t}=\mathbf{0})$ & $\mathbf{f}_{\mathbf{S m} / \mathbf{N d}}$ & $\begin{array}{c}\mathbf{T}_{\mathbf{D M}} \\
(\mathbf{G a})\end{array}$ & $\mathbf{E}_{\mathbf{N d}}(\mathbf{1 6 6 3})$ \\
\hline PMT0544 & MOTACUSAL & 7,538 & 32,078 & 0,1421 & 0,511964 & $-13,15$ & $-0,28$ & 2,30 & $-3,86$ \\
$\mathbf{B O 0 4 1 8}$ & TALCOSO & 10,025 & 47,460 & 0,1277 & 0,511927 & $-13,88$ & $-0,35$ & 1,97 & $-2,14$ \\
$\mathbf{C H 0 7 0 1}$ & CACHUELA & 9,086 & 53,341 & 0,1030 & 0,511781 & $-16,73$ & $-0,48$ & 1,73 & $-0,79$ \\
$\mathbf{C H 0 7 0 3}$ & CACHUELA & 9,755 & 55,755 & 0,1058 & 0,511807 & $-16,20$ & $-0,46$ & 1,74 & $-0,73$ \\
\hline
\end{tabular}

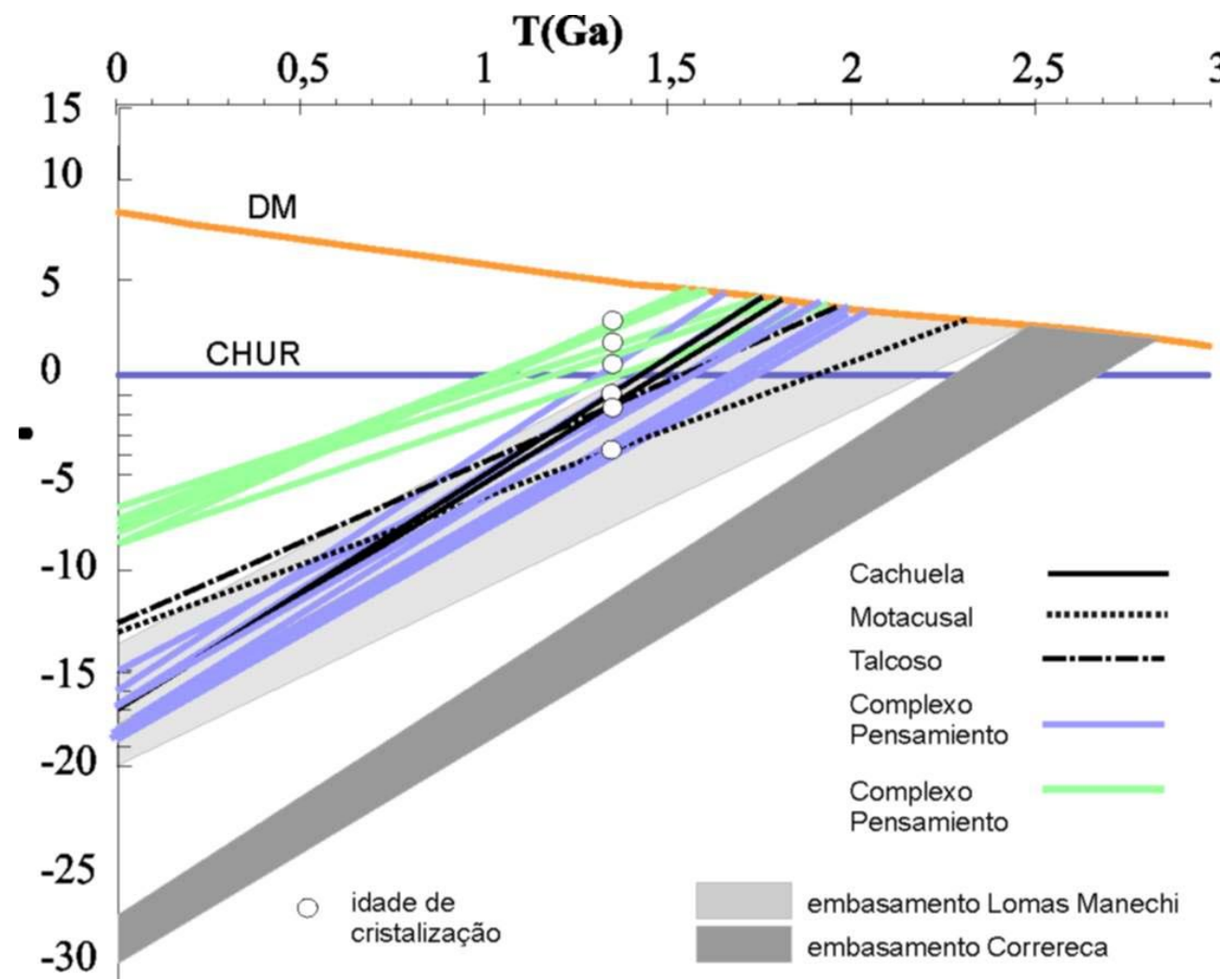

Figura 9 - Curva de evolução do Nd para as intrusões Cachuela, Motacusal e Talcoso. Os dados para o embasamento Lomas Manechis foi extraído de Matos et al. (2009) e o presente trabalho. A denominação Complexo Pensamiento reportado por Matos et al. (2009) refere-se a rochas geradas na orogenia San Ignácio.

Porem quando lançados os resultados aqui et al. (2009), os valores isotópicos no diagrama reportados adicionados dos resultados de Matos de evolução isotópica de $\mathrm{Nd}$ apresentam a 
formação de dois grupos distintos. Estes dois grupos sugerem podem ser interpretados como um grupo gerado com importante contribuição do embasamento representado pelas rochas do Complexo Lomas Maneches e um segundo manto derivado.

O primeiro, formado pelos granitos Diamantina e La Junta, com valores de $\mathrm{T}_{\mathrm{DM}}$ entre 1,65 e $2,04 \mathrm{Ga}$ e valores de $\varepsilon_{\mathrm{Nd}}(1330)$ entre $0,4 \mathrm{e}$ 4,3. O segundo grupo de granitos é formado pelas intrusões Piso Firme, San Cristobal Porvenir e San Martin. Estas rochas apresentam idades $\mathrm{T}_{\mathrm{DM}}$ entre 1,74 Ga $21,58 \mathrm{Ga}$ e valores de $\varepsilon_{\mathrm{Nd}}$ (1330) positivos entre $+2,75$ e $+1,48 \mathrm{Os}$ resultados isotópicos de $\mathrm{Sm}-\mathrm{Nd}$ do primeiro grupo indicam que as rochas foram formadas com importantes contaminações crustais.

Neste sentido, as amostras aqui estudadas representadas rochas das intrusões Cachuela, Motacusal e Talcoso apresentam similaridade com o primeiro grupo cujas assinaturas de isótopos de $\mathrm{Nd}$ indicam importante contaminação crustal com um componente mantélico e uma importante contribuição crustal. Por outro lado, o segundo grupo é formado por rochas com uma assinatura mantélica que prevalece em relação a possíveis componentes crustais.

\section{CORRELAÇÕES GEOLÓGICAS}

Neste item são abordadas as possíveis correlações geológicas das rochas aqui estudadas com as unidades no SW do Cráton Amazônico e no Terreno Arequipa-Antofalla.

Umas das primeiras tentativas em correlacionar rochas pré-cambrianas da Bolívia com as rochas do Brasil foi proposta por Litherland et al. (1986) e pode ser complementada pela evolução do conhecimento das unidades bolivianas e dos estudos recentes reportados sobre o Cráton Amazônico no Brasil (Tabela 6).

Novas correlações são possíveis a partir dos dados apresentados por Boger et al. (2005) e Matos et al. (2009) e os novos resultados apresentados neste trabalho (Figura 10). Em adição, trabalhos com revisões publicados por Teixeira et al. (1989; 2010) e Bettencourt et al. (2009) permitem avançar sobre a evolução conjunta do Paleo e Mesoproterozoico do SW do cráton amazônico. Porém, os resultados ainda não divulgados do granito Correreca não estavam disponíveis para as discussões dos trabalhos citados. Neste sentido, a correlação do terreno San Diablo com o terreno Arequipa-Antofalla parece ser a mais conveniente, na medida em que rochas de idade entre 1,92-1,89 Ga não são observadas no SW do cráton amazônico (Figura $10)$.

Uma primeira possível correlação é entre as idades dos zircões detríticos dos paragnaisses $\mathrm{La}$ Chiquitania e dos Xistos San Ignácio com as rochas do Complexo Jamari conforme descrito por Bittencourt et al (1999) cujas idades são por volta de $1,75 \mathrm{Ga}$.

Em adição, as rochas da suíte Alto Jauru, em Mato Grosso, apresentam idade entre 1,79 Ga e
$1,74 \mathrm{Ga}$, conforme reportado por Geraldes et al. (2001).

Estas rochas de Rondônia e Mato Grosso podem ter sido as fontes para os sedimentos dos gnaisses La Chiquitania na Bolívia. Estes gnaisses não apresentam unidades correlacionáveis no lado brasileiro.

Por outro lado, o embasamento compreendido pelos granulitos e gnaisses Lomas Maneches podem ser correlacionados com a Suíte Intrusiva Serra da Providência do Brasil. As idades obtidas na Bolívia e reportadas por Santos et al. (2008) e Boger et al. (2005) indicam rochas formadas entre $1617 \pm 6$ Ma e $1689 \pm 5$ Ma coerentes com a idade do granito San Pablo de $1617 \pm 4 \mathrm{Ma}$ reportados Bettencourt et al. (1999).

Por outra parte, os resultados sobre as rochas das intrusões Cachuela, Motacusal e Talcoso reportados neste trabalho como sendo da Orogenia San Ignácio, com idades por volta de 1,33 Ga (U-Pb em zircão por ICP-LA) podem ser correlacionados no Brasil com a Suíte Intrusiva Teotônio de idade $1406 \pm 32 \mathrm{Ma}$, a Suíte Alto Candeias de idade $1346 \pm 13$ Ma e a Suíte Intrusiva São Lourenço-Caripunas $1314 \pm 13 \mathrm{Ma}$ (U-Pb convencional segundo Bettencourt et al., 1999), cujos ambientes tectônicos foram interpretados como intracratônico (Figura 10).

Os granitos Taperas, El Carmen e Naranjito com idade entre 1071 até $1048 \mathrm{Ma}$, com valores de $\varepsilon_{(1000)}$, entre $-5,03$ e $-4,73$ (granitos crustais) podem correlacionar-se com a suíte Santa Clara com idade de 1081 até $1074 \mathrm{Ma}$ (Vargas, 2010). O granito Oriente Novo e os Granitos Jovens de Rondônia, de 998 até 974 Ma, não foram identificados na Bolívia.

As rochas do granito Correreca apresentam 
idades (1,9 Ga; Vargas, 2010) correlacionáveis às idades reportadas no Terreno ArequipaAntofalla descritos no norte do Chile e sul do Peru, conforme dados reportados por Tosdal (1996). Neste terreno localizado nos Andes, as rochas apontam idades de cristalização entre 1,90 e 1,75 Ga, além de idades metamórficas entre
1,10 e 1,00 Ga. É importante notar que no Terreno Arequipa-Antofalla não são observadas rochas de idades entre 1,70 e 1,30 Ga, sugerindo que este terreno não apresentava correlações com os terrenos no Pré-cambriano boliviano onde ocorrem as rochas da Orogenia San Ignácio e Lomas Manechi.

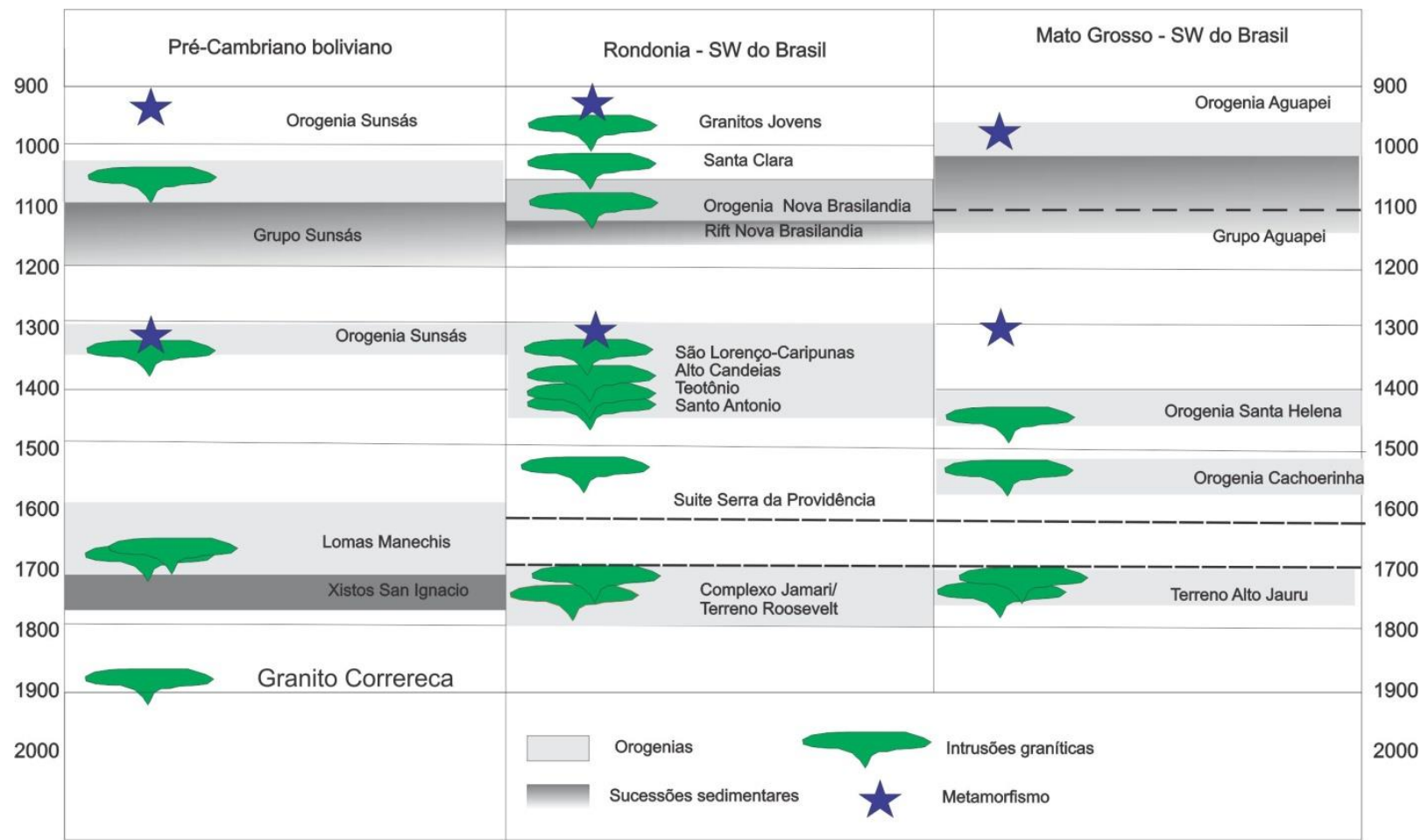

Figura 10 -Quadro comparativo entre as unidades geológicas da Bolívia e do Brasil (Rondônia e Mato Grosso).

\section{DISCUSSÕES}

Os resultados químicos e isotópicos das rochas aqui estudadas indicam protólitos e processos de geração para estas rochas. As idades $\mathrm{U} / \mathrm{Pb}$ (em zircão) obtidas para estas rochas situam-se entre 1307 e $1333 \mathrm{Ma}$, dados estes que marcam o período de cristalização da Orogenia San Ignácio (Rizzoto \& Quadros, 2007).

De forma complementar, estes autores apresentam idades de 1,32 Ga em Rondônia para o Complexo Colorado. Estes resultados similares para o Complexo Pensamiento sugerem um importante evento gerador de rochas granitóides no Pré-cambriano boliviano.

As idades aqui reportadas são similares às idades U-Pb obtidas em zircões pelo método SHRIMP por Boger et al. (2005) entre $1334 \pm 12$ e $1320 \pm 11 \mathrm{Ma}$.

Da mesma forma, Matos et al. (2009) reportaram resultados similares $\mathrm{U}-\mathrm{Pb}$ obtidas em zircão pelo método SHRIMP, das rochas interpretadas como sin-tectônicas a tarditectônicas dos plútons La Junta e San Martin, com valores de $1347 \pm 21$ Ma e $1373 \pm 20 \mathrm{Ma}$, respectivamente (Tabela 6)

Os dados de litogeoquímica e isótopos de $\mathrm{Nd}$ aqui reportados não são conclusivos em termos de ambiente tectônico para a formação das intrusões Cachuela, Motacusal e Talcoso.

Os resultados das composições químicas destas rochas sugerem um ambiente anorogênico (granitos tipo-A), conforme apresentados nos diagramas de Pearce et al. (1984).

Os diagramas multielementares também indicam ambiente intraplacas para a formação destes granitos.

Estas hipóteses de ambiente de formação para os granitos aqui estudados são corroboradas pelos resultados de $\mathrm{Sm}-\mathrm{Nd}$, de forma que os valores negativos de $\varepsilon_{\mathrm{Nd}}$ (1330) entre $-0,77$ e $-3,86$ sugerem uma importante participação de crosta no magma gerador destas rochas (Whalen et al., 1987; Ramo, 1991).

Porém, quando se analisa conjuntamente os resultados de Boger et al. (2005) e Matos et al. (2009), observa-se a existência de dois grupos de rochas formadas durante o magmatismo San 
Ignácio.

Os dois grupos podem ter como ambiente de formação de arcos magmáticos com rochas manto derivadas, mas com contribuições variadas de crostas mais antigas. Neste sentido, os granitos aqui estudados podem fazer parte do grupo de rochas derivadas do manto formadas durante a evolução do arco magmático mesoproterozoico, conforme proposto pelos investigadores acima referidos

Tabela 6 - Síntese dos dados geocronológicos para (U-Pb, Pb-Pb em zircão), para as rochas da orogenia San Ignácio.

\begin{tabular}{l|l|l|l|l}
\hline $\mathbf{N} \mathbf{0}$ & UNIDADE & IDADE (MA) & DESCRIÇÃO & REFERÊNCIAS \\
\hline $\mathbf{1}$ & Talcoso & $1333 \pm 68$ & Granodiorito & Este trabalho \\
\hline $\mathbf{2}$ & Motacusal & $1330 \pm 36$ & Monzogranito & Este trabalho \\
\hline $\mathbf{3}$ & Cachuela & $1307 \pm 7$ & Granodiorito & Este trabalho \\
\hline $\mathbf{4}$ & Rio Fortuna & $1336 \pm 3$ & ortognaisse & Santos et al. (2006, 2008) \\
\hline $\mathbf{5}$ & San Andrés & $1275 \pm 7$ & granito & Santos et al. ( 2008) \\
\hline $\mathbf{6}$ & Santa Rita & $1319 \pm 6$ & ortognaisse & Boger et al. (2005) \\
\hline $\mathbf{7}$ & San Rafael & $1334 \pm 12$ & granito & Boger et al. (2005) \\
\hline $\mathbf{8}$ & La Junta & $1347 \pm 21$ & granito & Matos et al. (2009) \\
\hline $\mathbf{9}$ & Diamantina & $1340 \pm 20$ & granito & Matos et al. (2009). \\
\hline $\mathbf{1 0}$ & Lomas Manechi & $1334 \pm 2$ borda de zircão & Gnaisse (idade de metam.) & Santos et al. (2006,2008) \\
\hline $\mathbf{1 1}$ & La Chiquitania & $1333 \pm 6$ (borda de zircão) & Gnaisse (idade de metam.) & Boger et al. (2005) \\
\hline $\mathbf{1 2}$ & La Chiquitania & $1333 \pm 6$ (borda de zircão) & Gnaisse (idade de metam.) & Boger et al. (2005) \\
\hline
\end{tabular}

Os dados de litogeoquímica e isótopos de $\mathrm{Nd}$ aqui reportados não são conclusivos em termos de ambiente tectônico para a formação das intrusões Cachuela, Motacusal e Talcoso. Os resultados das composições químicas destas rochas sugerem um ambiente anorogênico (granitos tipo-A), conforme apresentados nos diagramas de Pearce et al. (1984).

Os diagramas multielementares também indicam ambiente intraplacas para a formação destes granitos.

Estas hipóteses de ambiente de formação para os granitos aqui estudados são corroborados pelos resultados de $\mathrm{Sm}-\mathrm{Nd}$, de forma que os valores negativos de $\varepsilon_{\mathrm{Nd}}$ (1330) entre $-0,77$ e $-3,86$ sugerem uma importante participação de crosta no magma gerador destas rochas (Whalen et al., 1987; Ramo, 1991). Porém, quando se analisa conjuntamente os resultados de Boger et al. (2005) e Matos et al. (2009), observa-se a existência de dois grupos de rochas formadas durante o magmatismo San Ignácio. Os dois grupos podem ter como ambiente de formação de arcos magmáticos com rochas manto derivadas, mas com variadas contribuições de crostas mais antigas. Neste sentido, os granitos aqui estudados podem fazer parte do grupo de rochas derivadas do manto formadas durante a evolução do arco magmático mesoproterozoico, conforme proposto pelos investigadores acima referidos.

\section{CONCLUSÕES}

Um importante evento gerador de plútons graníticos ocorreu entre 1330 e 1300 Ma no Précambriano boliviano, assim como na maior parte da Província Rondoniana (Bettencourt et al., 2009; Rizzotto et al., 2001), representando o evento orogênico Rondoniano-San Ignácio (Cordani \& Teixeira, 2007). As coletas de campo realizadas permitiram a identificação de 3 corpos intrusivos com idades correlacionáveis ao evento San Ignácio. Neste sentido, foram obtidos resultados U-Pb do Granodiorito Cachuela, com quimismo peraluminoso a metaluminoso, com idade de cristalização de $1307 \pm 7 \mathrm{Ma}(\mathrm{U}-\mathrm{Pb})$, tipo-A, conforme sugerido pelos valores de $\varepsilon_{(1333)}$ entre -0.77 até $-0,96$.

A intrusão Motacusal apresenta composição sienogranítica a monzogranítica, com afinidade peraluminosa de médio $\mathrm{K}$, gerados num ambiente anorogênico (tipo-A), com $\varepsilon_{(1333)}-3,83$, com idade de cristalização de $1330 \pm 36 \mathrm{Ma}$. Por sua vez, o Granodiorito Talcoso também apresenta composição granodiorítica, com afinidade 
peraluminoso, formado a $1333 \pm 68 \mathrm{Ma}$, com assinatura de granito tipo-A com $\varepsilon_{\mathrm{Nd}}(1,33 \mathrm{Ga})-$ 2,13. Os dados isotópicos de $\mathrm{Nd}$ indicam uma participação preponderante de material crustal na fonte magmática sugerindo que o magmatismo do evento San Ignácio teve como fonte parcial de rochas da crosta mais antiga formada durante a orogênese Lomas Manechi.

A hipótese das rochas do evento San Ignácio ser juvenil é defendida por Matos et al. (2009). Em vista dos resultados deste trabalho em conjunto (Tabela 6) com os dados reportados na literatura, os resultados apresentados neste trabalho das intrusões Cachuela, Talcoso e Motacusal se enquadram no contexto da Orogenia San Ignácio. Neste sentido, os granitóides em estudo se encontram entre $1307 \pm$ $7 \mathrm{Ma}$ e $1333 \pm 68 \mathrm{Ma}$ concordando com publicações recentes (Boger et al., 2005; Santos et al., 2008; Matos et al., 2009) para o magmatismo mais expressivo em termos de área do Pré-cambriano boliviano que e forçam a ideia de que um arco magmático juvenil mesoproterozoico finalizou a evolução acrescionária da Província Rondoniana-San Ignácio.

\section{REFERÊNCIAS}

ADAMEK, P.M.; TROENG, B.; LANDIVAR, G.; LLANOS, A.; MATOS, R. Evaluación de los recursos minerales del Distrito San Ramón. Boletín del Servicio Geológico de Bolivia, n. 10, 77 p., 1996.

AMARAL, G. Geologia pré-Cambriana da região Amazônica São Paulo, 212 p. 1974. Tese (Livre docência), 1974. São Paulo.

BETTENCOURT, J.S.; LEITE, W.B.; RUIZ, A.S.; MATOS, R.; PAYOLLA, B.L.; TOSDAL, R.M. The Rondonian-San Ignacio Province in the SW Amazonian Craton: an overview. Journal of South American Earth Sciences, doi: 10.1016/j.jsames.2009.08.006. 2009

BOGER， S.D.; RAETZ，M.; GILES，D.; ETCHART, E.; FANNING, M.C. U-Pb age data from the Sunsas region of Eastern Bolívia, evidence for the allochthonous origin of the Paragua Block. Precambrian Research, v. 139, p. 121-146, 2005.

BOYNTON, W.V. Geochemistry of the rare earth elements: meteorite studies. In: Henderson, P. (ed.), Rare earth element geochemistry. Elsevier, p. 63-114, 1984

CHAPPEL, B.W. \& WHITE, A.R.J., Two contrasting granite types: 25 years later. Australian Journal of Earth Sciences, v. 48: p. 489-499, 2001.

CHEMALE, JR. I.F.; DUSSIN, A. F.; ALKMIM, F.; MAXIMILIANO, S.M.; QUEIROGA, G.; ARMSTRONG, R.; SANTOS, M.N. Unravelling a Proterozoic basin history through detrital zircon geochronology: The case of the Espinhaço Supergroup, Minas Gerais, Brazil. Gondwana Research, v. 22, Issue 1, p. 200-206, 2012.

CORDANI, U.S.; TASSINARI, C.C.G.; TEIXEIRA, W.; BASEI M.A.S.; KAWASHITA, K. Evolução tectônica da Amazônia com base nos dados geocronológicos. In: CONGRESSO DE GEOLOGIA CHILENO, Actas...Lima: v. 4, p. 137-148, 1979.

CORDANI, U.G. \& NEVES, B.B.B. The geological evolution of South America during the Archean and Early Proterozoic. Revista Brasileira de Geociências, v. 12, n. 1-3, p. 78-88, 1982.

CORDANI, U.G. \& TEIXEIRA, W. Proterozoic Accretionary belts in the Amazonian craton. In: HATCHRER, R.D.JR.; CARLSON, M.P.; MCBRIDE, J.H.; MARTINEZ CATALÁN, J.R. (org). The 4D Framework of Continental Crust. GSA Memoir. Boulder, Colorado. Geological Society of America Book (eds), v. 200, p. 297 - 320, 2007.

CORFU, F. Differential response of U-Pb system in co-existing accesory minerals, Winnipeg River sub-province, Canadian Shield: implications for Archean cristal growth and stabilization. Contribution to Mineralogy and Petrology, v. 98, p. $312-325,1988$

D'AGRELLA-FILHO, M.S.; TOHVER, E.; SANTOS, J.O.S.; ELMING, S.-A.; TRINDADE, R.I.F.; PACCA, I.I.G.; GERALDES, M.C. Direct dating of paleomagnetic results from
Precambrian sediments in the Amazon craton: Evidence for Grenvillian emplacement of exotic crust in SE Appalachians of North America. Earth and Planetary Science Letters, v. 267, p. 188-199. 2008.

D'AGRELLA-FILHO, M.S.; TRINDADE, R.I.F, ELMING S.Å., TEIXEIRA, W, YOKOYAMA, E.; TOHVER, E.; GERALDES, M.C.; PACCA, IIG, BARROS, M.A.S, RUIZ, A.S. The $1420 \mathrm{Ma}$ Indiavaí Mafic Intrusion (SW Amazonian Craton): Paleomagnetic results and implications for the Columbia supercontinent. Gondwana Research, v. 22, n. 3-4, p. 956-973, 2012

DE LA ROCHE, H.; LETERRIER, J.; GRANDE CLAUDE, P.; MARCHAL, M. A classification of volcanic and plutonic rocks using R1-R2 diagrams and major elements analyses - its relationships and current nomenclature. Chemical Geology, v. 29, p. $183-210,1980$

DEPAOLO, D.J. Neodymium Isotope Geochemistry. SpringerVerlag. Mineral and Rocks, v. 20, 181 p., 1988.

EBY, N.G. Chemical subdivisión of the A-tipe granitoids: Petrogenetic and tectonic implications. Geology, v. 20, p. 641644, 1992

FLETCHER, C.J.N. La geología y potencial de minerales del área de Concepción (Cuad SE. 20-2). Boletín del Servicio Geológico de Bolivia, v. 2, 69 p., 1979.

GERALDES M.C.; VAN SCHMUS, W.R.; CONDIE, K.C.; BELL, S.; TEIXEIRA, W. BABINSKI, M. Proterozoic Geologic Evolution of the SW Part of the Amazonian Craton in Mato Grosso State, Brazil. Precambrian Research, v. 111, p. 91-128, 2001.

GERALDES, M.C.; TEIXEIRA, W.; HEILBRON, M. Lithospheric versus asthenospheric source of the SW Amazonian craton A-types granites: the role of the Paleo and Mesoproterozoic accretionary belts for their coeval continental suítes. Episodes, v. 27, n. 3, p. 185-189, 2004.

GERALDES, M.C.; NOGUEIRA, C.C.; VARGAS-MATOS, G.L.; MATOS, R.; TEIXEIRA, W.; VALENCIA, V.; RUIZ, J. $\mathrm{U}-\mathrm{Pb}$ detrital zircon ages from the Aguapei Group (Brazil): Implications for the geological evolution of the SW border of the Amazonian Craton. Precambrian Research, v. 1, p. 1-26, 2014, 2013.

HOFFMAN, P.F. Did the breakout of Laurentia turn Gondwanaland inside out ?. Science, v. 252, p. 1409-1412, 1991.

LÊ MAITRE, R.W. A classification of igneous rocks and glossary of terms. Blackwell Scientific Publ., Oxford, 193 p. 1989.

LITHERLAND, M.; ANNELS, R.N.; APPLETON, J.D.; BERRANGÉ, J.P.; BLOOMFIELD, K.; BURTON, C.C.J.; DARBYSHIRE, D.P.F.; FLETCHER, C.J.N., HAWKINS, M.P.; KLINK, B.A.; LLANOS, A.; MITCHEL, W.I.; O'CONNORS, E.A.; PITFIELD, P.E.J.; POWER, G.; WEBB, 
B.C. The geology and mineral resources of the Bolivian Precambrian Shield. Overseas Memoir British Geological Survey, v. 9, 153 p., 1986.

LUDWIG, K.R. Isoplot 3.00. Berkeley Geochronology Center, Special Publication, v. 4, 70 p., 2003.

MANIAR, P.D. \& PICCOLI P.M. Tectonic discrimination of granitoids. Geological Society of American Bulletin, v. 101, p. 635-643, 1989.

MATOS, R., TEIXEIRA, W.; GERALDES, M.C.; BETTENCOURT, J.S. Geochemestry and isotopic evidence of the Pensamiento Grannitoid Complex, Rondonian - San Ignácio province, easter Precambrian Shield of Bolivia: petrogenetic constrains for a Mesoproterozoic magmatic arc setting. Revista Geologia USP Série Científica, v. 9, n. 2, p. $89-117,2009$.

MENEZES, R.G., SILVA, P.C.S., SILVA, L.C., TAKAHASHI, A.K., LOPEZ, I., BEZERRA, J.R.I. Geologia da Folha Pontes e Lacerda - SD-21-Y-C-II. Levantamentos geológicos Básicos do Brasil, CPRM, Brasília, 126 p., 1993.

PEARCE, J.A.; HARRIS N.B.W.; TINDLE, A.G. Trace elements discrimination diagrams for the tectonic interpretation of granitic rocks. Journal of Petrology, v. 25, n. 4, p. 956-983, 1984.

RAMO, O.T. Petrogenesis of the Proterozoic rapakivi granites and related basic rocks of southeastern Fennoscandia: Nd and $\mathrm{Pb}$ isotopic and general geochemical constrain. Geological Survey of Finland Bulletin, v. 355, p. 161. 1991.

RIZZOTTO, G. J., LIMA, E. F., CHEMALE JUNIOR, F., Geologia do Grupo Nova Brasilândia, sudeste de Rondônia, acresção continental e implicações geotectônicas. In N. REIS, J. e MONTEIRO, M.A.S (coord). Contribuições à Geologia da Amazônia, Sociedade Brasileira de Geologia, v. 2, p. 324 442, 2001.

RIZZOTTO, G.J. \& QUADROS, L.Q. 2007. Margem passiva e granitos Orogênicos do Ectasiano em Rondônia. In: SIMPÓSIO DE GEOLOGIA DA AMAZÔNIA, X, Porto Velho. 2007. Anais...Porto Velho: Sociedade Brasileira de Geologia, Cdrom.

SANTOS, J.O.S.; HARTMANN, L.A.; GAUDETTE, H.E.; GROVES, D.I.; MCNAUGHTON, N.J.; FLETCHER, I.R. A new understanding of the provinces of the Amazon Craton based on integration of field mapping and $\mathrm{U}-\mathrm{Pb}$ and $\mathrm{Sm}-\mathrm{Nd}$ geochronology. Gondwana Research, v. 3, p. 453-488, 2000.

SANTOS, J.O.S., RIZZOTTO, G.J., McNAUGHTON, N.J.; MATOS, R.; HARTMAN, L.A.; CHEMALE, Jr.F.; POTTER, P.E.; QUADROS, M.L.E.S. The age and autochthonous evolution of Sunsás Orogen in West Amazon Craton. Precambrian Research, v. 165, p. 120 - 152, 2008.

SATO, K.; TASSINARI, C.C.G.; KAWASHITA, K.; PETRONILHO, L. O. Método geocronológico Sm-Nd no IG/USP e suas aplicações. Anais da Academia Brasileira de Ciências, v. 67, p. 313-336, 1995.
TASSINARI, C.C.G. \& MACAMBIRA, M.J.B. A Evolução tectônica do Cráton Amazônico. In: MANTESSO NETO, V., BARTORELLI, A., CARNEIRO, C.D.R., NEVES, B.B.B. Geologia do Continente Sul-Americano: Evolução da Obra de Fernando Flávio Marques de Almeida. 672 p., 2004.

TASSINARI, C.G.; BETTENCOURT, J.S.; GERALDES, M.C.; MACAMBIRA, M.J.B.; AND LAFON, J.M. The Amazonian craton. In: CORDANI, U.; MILANI, E.J.; THOMAZ FILHO, A.; CAMPOS, D.A. (eds.), Tectonic evolution of South America, 31st INTERNATIONAL GEOLOGICAL CONGRESS, Rio de Janeiro, Brazil, p. 41- 95, 2000.

TEIXEIRA, W.; TASSINARI, C.C.G.; CORDANI, U.G.; KAWASHITA, K. A review of the geochronology of the Amazonian craton: tectonic implication. Precambrian Research, v. 42, p. 213-227, 1989.

TEIXEIRA, W.; GERALDES, M.C.; MATOS, R.; RUIZ, A.S.; SAES, G.; VARGAS-MATTOS, G. A review of the tectonic evolution of the Sunsás belt, SW Amazonian Craton. Journal of South American Earth Sciences, v. 29, p. 47-60, 2010.

TOHVER, E.; VAN DER PLUIJM, B.A.; SCANDOLARA, J.E.; GERALDES, M.C. Rodinia and the Amazonia-Laurentia Connection: preliminary D.P.T. results in western Brazil. Denver. 2000. GSA ANNUAL MEETING. Abstract...Denver, 2000.

TOHVER, E.; VAN DER PLUJIN, B.; TEIXEIRA, W.; GERALDES, W.; GERALDES, M.C.; BETTENCOURT, J.; RIZZOTO, G. Restored transect across the exhumed Grenville orogen of Laurentia and Amazonia, with implications for crustal architecture. Geology, v. 34, p. 669-672, 2006.

TOSDAL, R.N. The Amazonia-Laurentia connection as viewed from the Middle Proterozoic rocks in the central Andes, western Bolivia and northern Chile. Tectonics, v. 15, p. 827-842, 1996.

VARGAS-MATTOS, G.L. Geocronologia U-Pb em granitos pós e sintectônicos da Orogenia Sunsás, no Cráton Amazônico da Bolívia. Rio de Janeiro, 2006. 107. Dissertação (Mestrado), Universidade do Estado do Rio de Janeiro.

WHALEN, J.B.; CURRIE, K.L.; CHAPPELL, B.W. A-type granites: chemical characteristics, discrimination and petrogenesis. Contributions Mineralogy Petrology, v. 95, n. 407-19, 1987 